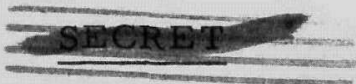

Contract No. W-7405-eng-92
Report No. BMI-1200

C-86 Nuclear Rocket Engines

(M-3679, 19th Ed.)

This document consists of 60 pages, No. 35 of 67 copies, Series A.

\title{
CARBIDE COATINGS ON GRAPHITE
}

by

John M. Blocher, Jr.

Carl J. Ish

Don P. Leiter

Layne F. Plock

Ivor E. Campbell

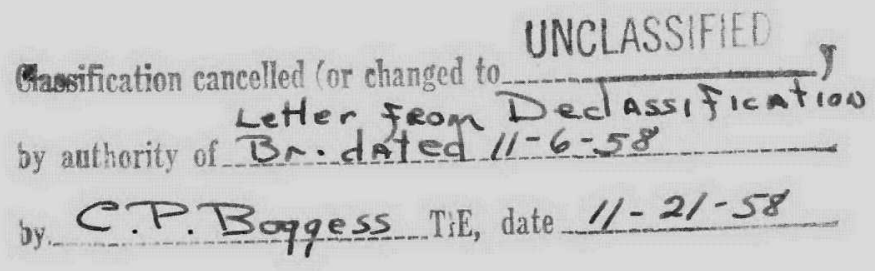

June 28, 1957

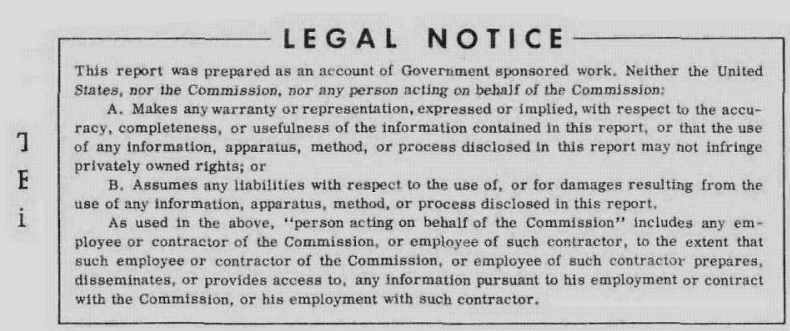

BATTELLE MEMORIAL INSTITUTE 505 King Avenue

Columbus 1, Ohio

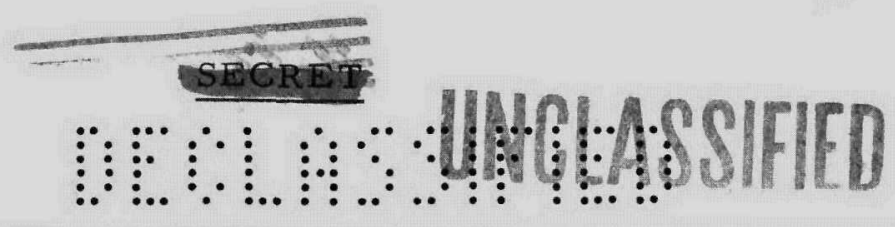




\section{DISCLAIMER}

This report was prepared as an account of work sponsored by an agency of the United States Government. Neither the United States Government nor any agency Thereof, nor any of their employees, makes any warranty, express or implied, or assumes any legal liability or responsibility for the accuracy, completeness, or usefulness of any information, apparatus, product, or process disclosed, or represents that its use would not infringe privately owned rights. Reference herein to any specific commercial product, process, or service by trade name, trademark, manufacturer, or otherwise does not necessarily constitute or imply its endorsement, recommendation, or favoring by the United States Government or any agency thereof. The views and opinions of authors expressed herein do not necessarily state or reflect those of the United States Government or any agency thereof. 


\section{DISCLAIMER}

Portions of this document may be illegible in electronic image products. Images are produced from the best available original document. 


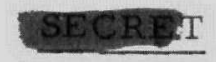

3 and 4
Report No. BMI-1200

C - 86 Nuclear Rocket Engines

(M-3679, 19th Ed.)
Copy No.

1

2

3

4

5

6

7

8

9

10

11-14

15

16

17

18-19

20

21

22

23

24

25-26

27

28-31

32

33-34

35-59

60-67

\section{Distribution}

Aerojet-General Corporation (Thomas Beehan)

AF Plant Representative, Baltimore

AF Plant Representative, Long Beach

Air Research and Development Command (RDZPSP)

Air Technical Intelligence Center

ANP Project Office, Fort Worth

Albuquerque Operations Office

Armed Forces Special Weapons Project, Sandia

Armed Forces Special Weapons Project, Washington

Assistant AF Plant Representative, Downey

Atomic Energy Commission, Washington

Bureau of Ordnance

Bureau of Ordnance (SP-209)

Headquarters, Air Force Special Weapons Center

Los Alamos Scientific Laboratory

National Advisory Committee for Aeronautics, Cleveland

National Advisory Committee for Aeronautics, Washington

North American Aviation, Inc. (Missile Development Division)

Redstone Arsenal

San Francisco Operations Office

USAF Project RAND

U. S. Naval Ordnance Test Station

University of California Radiation Laboratory, Livermore

Western Development Division

Wright Air Development Center (WCOSI-3)

Technical Information Service Extension, Oak Ridge

Battelle Memorial Institute 
ABSTRACT . . . . . . . . . . . . . . . . . . . 7

INTRODUCTION . . . . . . . . . . . . . . . . . . . . . . . 7

Limiting-Pressure Determinations . . . . . . . . . . . . 8

Thermodynamic Treatment of Limiting-Pressure Data . . . . . . . 9

Coating of Blowpipe Specimens . . . . . . . . . . . . . . . 16

Coating of Uranium-Impregnated Specimens . . . . . . . . . . . 29

Diffusion of Carbon in Carbides . . . . . . . . . . . . . . 34

ACKNOWLEDGMENT . . . . . . . . . . . . . . . . . . 38

REFERENCES . . . . . . . . . . . . . . . . . . . 38

APPENDIX A

APPARATUS AND PROCEDURE FOR LIMITING-PRESSURE

DETERMINATIONS

APPENDIX B

COATING OF BLOWPIPE SPECIMENS.$\quad$. . . . . . . . . . . 53

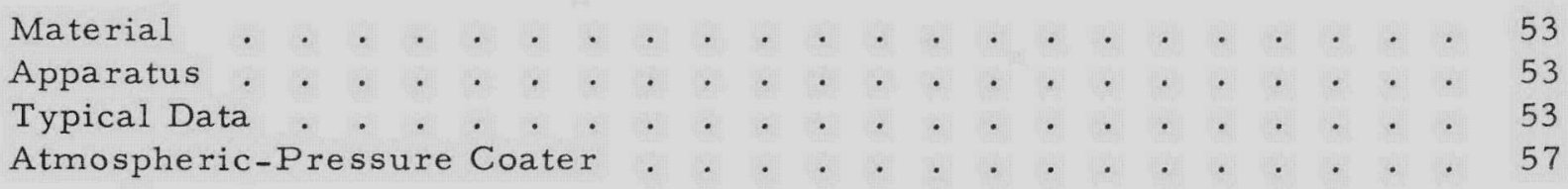

APPENDIX C

THERMODYNAMIC ANALYSIS OF PRESSURE RANGE FOR

METAL-FREE CARBIDE FORMATION 


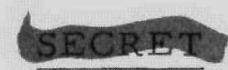

\section{CARBIDE COATINGS ON GRAPHITE}

John M. Blocher, Jr., Carl J. Ish, Don P. Leiter, Layne F. Plock, and Ivor E. Campbell

1

A method has been developed for the uniform coating of graphite tubes with carbides of niobium, tantalum, and zirconium by thermal decomposition of their respective halide vapors. Conditions of coating temperature and pressure are so chosen as to prevent the deposition of metal, but to permit the formation of the carbide as rapidly as carbon can diffuse to the surface. If the carbon diffusion can be made the rate-limiting step, the coating process becomes selfregulating and uniform thickness results. The limits of the temperature-pressure range have been determined experimentally for the thermal decomposition of zirconium iodide and of the chlorides and bromides of niobium, tantalum, and zirconium.

With the successful development of coating equipment and definition of conditions, 99 blowpipe test specimens were coated with uniform, continuous, and adherent layers of the carbides in three ranges of thickness, light (0.001 in.), medium (0.005 in.), and heavy (0.01 in.).

Determinations were maae of the coefficient for the diffusion of carbon in zirconium carbide as a function of temperature.

Exploratory work on small specimens of graphite impregnated with $7 \mathrm{w} / \mathrm{o}$ uranium indicated that the coating results were essentially unchanged, but that loss of uranium occurred. Means of avoiding the loss of uranium are discussed.

\section{INTRODUCTION}

The research described in this report was engendered by the problem of uniformly coating graphite with carbides of niobium, tantalum, and zirconium on the inside of long bores. Although other methods of coating were considered, vapor deposition offered the greatest promise of forming continuous, adherent coatings. However, as normally practiced, vapor deposition has the disadvantage that considerable attention must be given to the vapor-flow pattern to avoid nonuniformity. Adjustment of the vapor-flow pattern is practical in coating some shapes, but serious limitations are imposed in the case of small-bore tubing. For example, if the coating were to be formed in the usual manner $(1)$ by the hydrogen reduction of a metal halide-hydrocarbon mixture, one would expect it to be thicker at the vapor-entrance end of the bore than at the vapor-exit end. The same difficulty would be encountered in the deposition of a layer of metal to be later converted to carbide by interdiffusion at elevated temperatures.

The multivalent character of the transition elements involved in this work holds the key to a method of avoiding nonuniformity by making the rate of formation of the coating dependent on the rate of diffusion of carbon from the base through the carbide coating. This can best be shown by example.

(1) References at end of text.

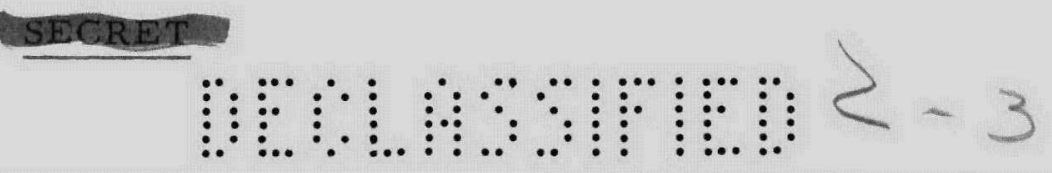


The thermal decomposition of zirconium iodide vapor at low pressures has long been used as a method of preparing high-purity zirconium metal. (2) The over-all reaction is $\mathrm{ZrI}_{4}(\mathrm{~g}) \rightarrow \mathrm{Zr}(\mathrm{s})+4 \mathrm{I}(\mathrm{g})$. However, owing to the stability of the lower iodides, $\mathrm{ZrI}_{3}$ and $\mathrm{ZrI}_{2}$, reactions of the type $\mathrm{ZrI}_{4}(\mathrm{~g})+\mathrm{Zr}(\mathrm{s}) \rightarrow 2 \mathrm{ZrI}_{2}(\mathrm{~g})$ may also occur. In fact, as the pressure of $\mathrm{ZrI}_{4}$ is increased, reactions of the second type become more important and, as equilibrium calculations will show, at any given temperature there exists a limiting tetraiodide pressure below which zirconium will be deposited and above which metal will be consumed. This situation is general with the gaseous halides of the transition metals.

It can also be shown that a limiting pressure exists at a higher level for reactions of the type $\mathrm{ZrI}_{4}(\mathrm{~g})+\mathrm{C}(\mathrm{s}) \rightarrow \mathrm{ZrC}(\mathrm{s})+4 \mathrm{I}(\mathrm{g})$. Thus, by operating in the region above the limiting pressure for metal deposition and below the limiting pressure for carbide formation, one can avoid the deposition of metal and form only the carbide. Moreover, if the vapor-flow rate is made sufficiently high, the rate of formation of the coating becomes limited, not by kinetics or mass-transfer considerations at the vapor-carbide interface, but by the rate of diffusion of carbon through the carbide coating. Since the rate of diffusion is inversely proportional to the thickness of the coating, the thickness increase becomes self-regulating and independent of vapor-flow considerations over a wide range.

The research reported here was carried out to develop and apply this technique to the coating of blowpipe specimens for the University of California Radiation Laboratory at Livermore, California, where the protection of the graphite from hightemperature corrosion of certain gases was to be tested.

A twofold plan of attack was adopted, consisting of a fundamental and an engineering approach. In the fundamental program, the pressure-temperature limits for metal and carbide formation were to be determined along with such other information as might be applicable, while, in the engineering program, a specimen plater was to be developed having sufficient flexibility to be operable in the ranges indicated by the fundamental work.

\section{Limiting-Pressure Determinations}

The limiting pressures as functions of temperature were determined for metal and carbide formation by the thermal decomposition of zirconium iodide and of the chlorides and bromides of niobium, tantalum, and zirconium. Although it was not anticipated that all of these halides would be used in the coating of blowpipe specimens, data were obtained on their decomposition to provide the widest possible choice of conditions for the coating work. The iodides of niobium and tantalum were not considered, since it was predicted that, because of their low stability, formation of carbide in the absence of metal would have to be carried out in a temperature range so low as to make the rate of diffusion of carbon through the carbide impractically slow.

The technique of making these measurements is described in Appendix A. Briefly, it consisted of passing the metal halide vapor at controlled pressure over a resistively heated wire for metal deposition or a carbon rod for carbide formation, increasing the temperature of the deposition surface, and by monitoring the electrical resistance 
(and/or total emission in the case of the carbides), determining the temperature at which the wire or rod showed neither growth nor attack. Although it was possible to establish a true equilibrium temperature in several instances, the limit was established in most cases as a somewhat uncertain boundary between points of deposition and of no deposition or attack.

The results of this work are shown in Figures 1, 2, and 3, where the limiting pressures in millimeters of mercury are plotted on a logarithmic scale against the temperatures in degrees centigrade on a scale linear with the reciprocal of absolute temperature. The experimental points are shown in Appendix A.

These graphs, showing the pressure-temperature ranges favorable to carbide formation and unfavorable to metal deposition, served as the basis for the choice of conditions for coating blowpipe specimens.

$\mathrm{X}$-ray diffraction studies indicated that $\mathrm{NbC}, \mathrm{TaC}$, and $\mathrm{ZrC}$ were the principal carbides formed in the above work. However, although the monocarbide invariably formed adjacent to the graphite, it was possible, under pressure-temperature conditions toward the metal-deposition limit, to form mixtures of carbides (e.g., TaC and $\mathrm{Ta}{ }_{2}$ C) and metal, and, in some cases, carbides with reduced lattice parameters, indicating possible defect lattices or ranges of homogeneity. Where liquid or solid solubility, or intermediate carbides exist in the carbide-metal system, such coatings would be expected to form at equilibrium at some point between the pressure-temperature limits for carbide and metal deposition. A study of the coating properties as a function of coating conditions would be profitable. Unfortunately, time did not permit the adoption of such a program.

Figures 4, 5, and 6 are photomicrographs of typical coatings obtained in these experiments on small ATJ-grade graphite rods. Although there are microscopic discontinuities in the coatings, they are considered to be continuous from a macroscopic standpoint.

It should be noted that, in these runs, the rate of vapor flow was probably insufficient to permit the coating rate to be controlled by diffusion of carbon through the carbide. The coating times given should be interpreted with this condition in mind.

The adherence characteristic of the coatings prepared in this work is attributed, at least in part, to the fact that the great throwing power evident in Figures 4 , 5, and 6 locks the coating to surface irregularities. In all of the coatings prepared to date in the range 1900 to $2200 \mathrm{C}$, only one case of spalling was observed, and this was the result of oil vaporizing from a graphite adaptor which had been contaminated during machining. Thus, the carbides formed from carbon of the substrate were adherent without exception.

Thermodynamic Treatment of Limiting-Pressure Data

Since the existence of a limiting pressure in the thermal dissociation of a halide vapor requires the existence of a stable lower halide, it should be possible, in principle, to determine the nature and thermodynamic properties of the lower halides by properly analyzing the limiting-pressure data. 


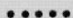

$\cdots \cdot:$

.......

:’:":

$\because \cdots$ N...

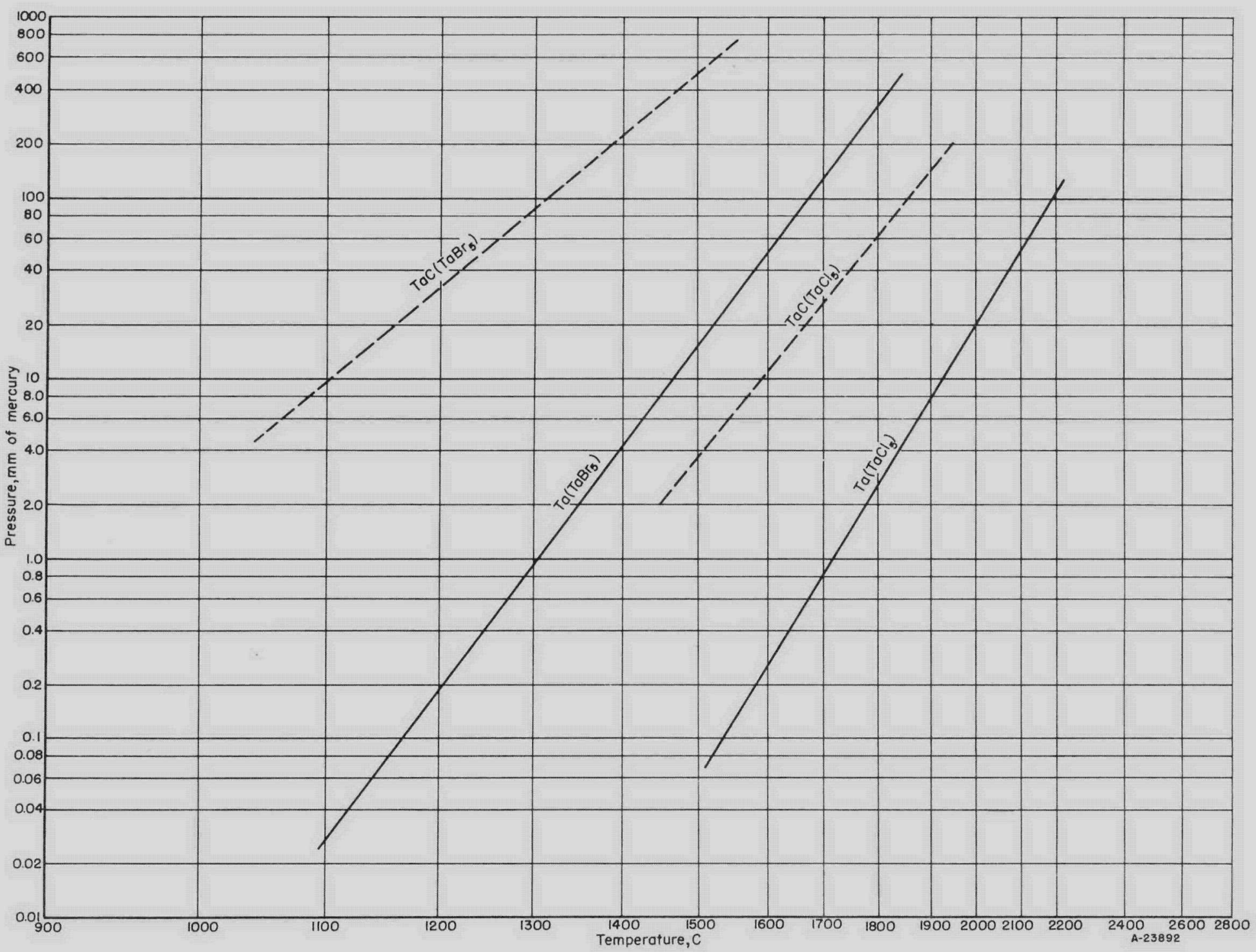
TANTALUN. (FULL LINE) B Y THERMAL DECOMPOSITION OF $\mathrm{TaCl}_{5}$ AND $\mathrm{TaBr}_{5}$ 
.....:.

$\because$.

$\because \because$

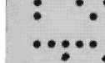

...

$\vdots \ldots .$.

$\therefore . .$.

$\vdots \ldots . .$.

.....

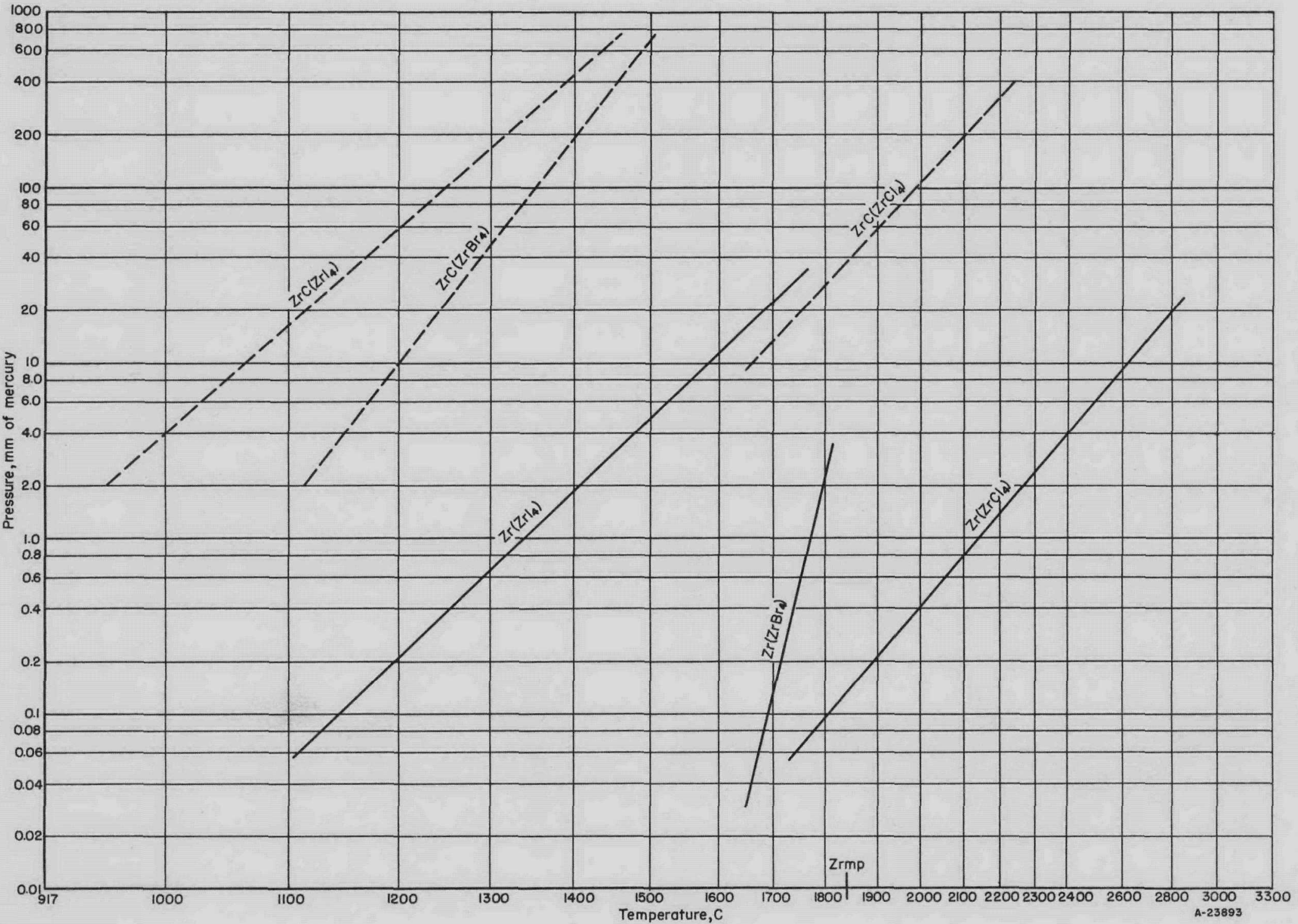

FIGURE 3. LIMITING PRESSURES FOR THE FORMATION OF ZrC ON CARBON (DASHED LINE) AND OF ZIRCONIUM (FULL LINE) BY THERMAL DECOMPOSITION OF $\mathrm{ZrCl}_{4}, \mathrm{ZrBr}_{4}$, AND $\mathrm{ZrI}_{4}$ 


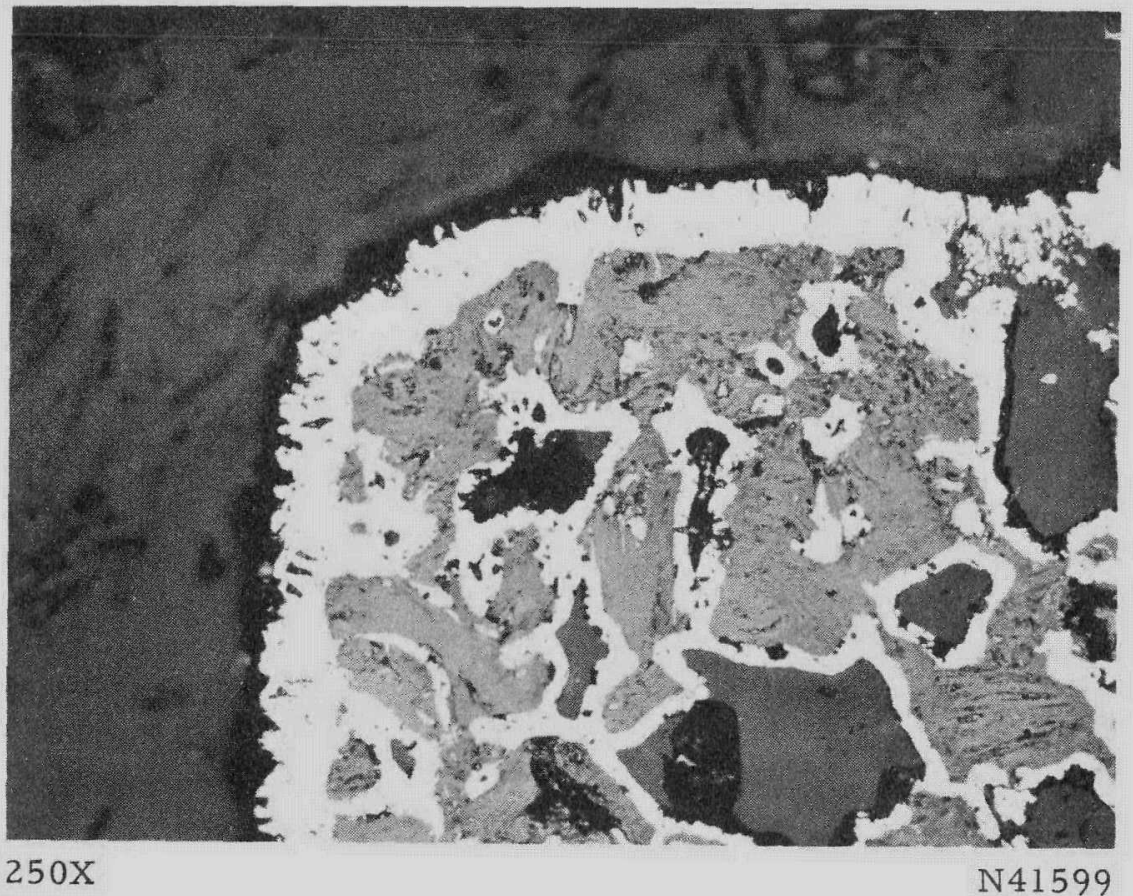

FIGURE 4. NIOBIUM CARBIDE COATING ON AT J GRAPHITE FORMED IN 45 MIN BY THERMAL DECOMPOSITION OF NbBr 5 AT 1200 TO 1500 C AT 100 MM OF MERCURY Run 12644-25.

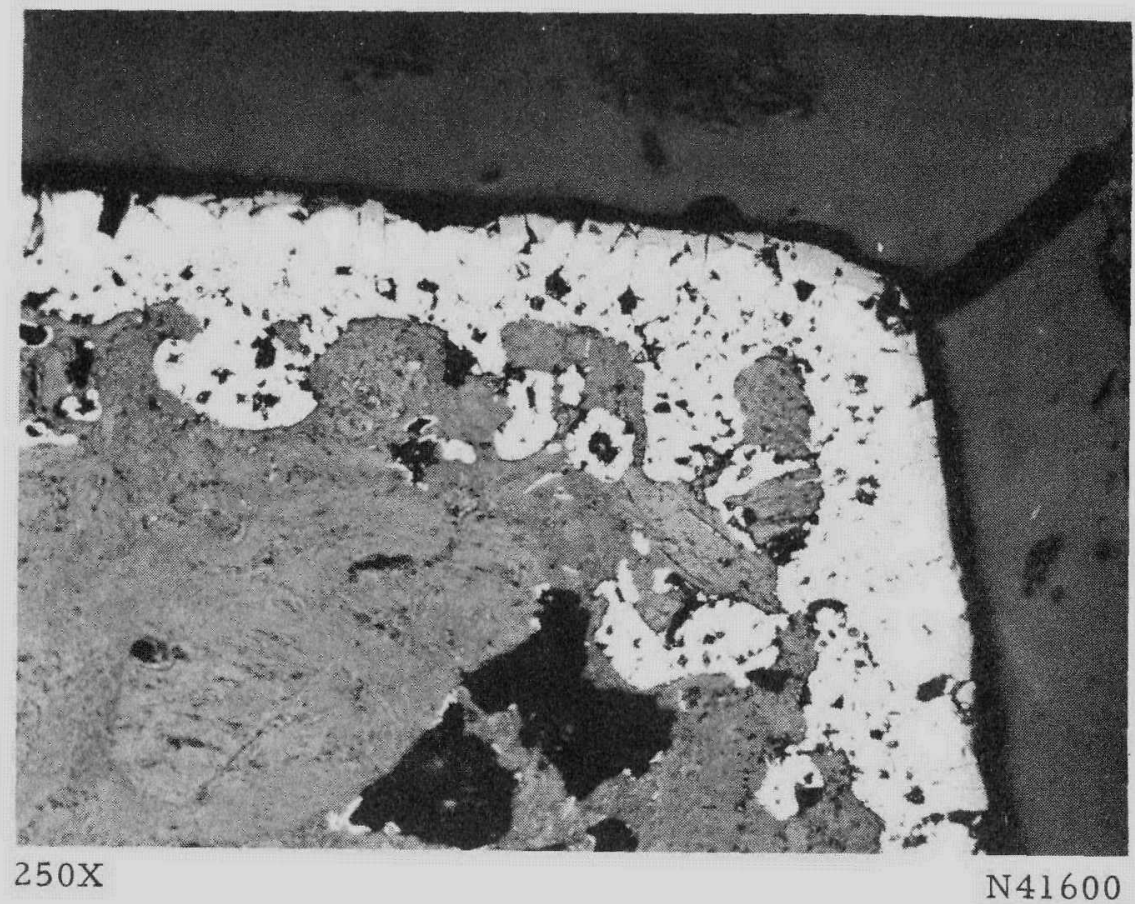

FIGURE 5. TANTALUM CARBIDE COATING ON ATJ GRAPHITE FORMED IN 10 MIN BY THERMAL DECOMPOSITION OF $\mathrm{TaCl}_{5} \mathrm{AT}$ 1890 TO 2000 C AT 48 MM OF MERCURY Run 12010-59. 


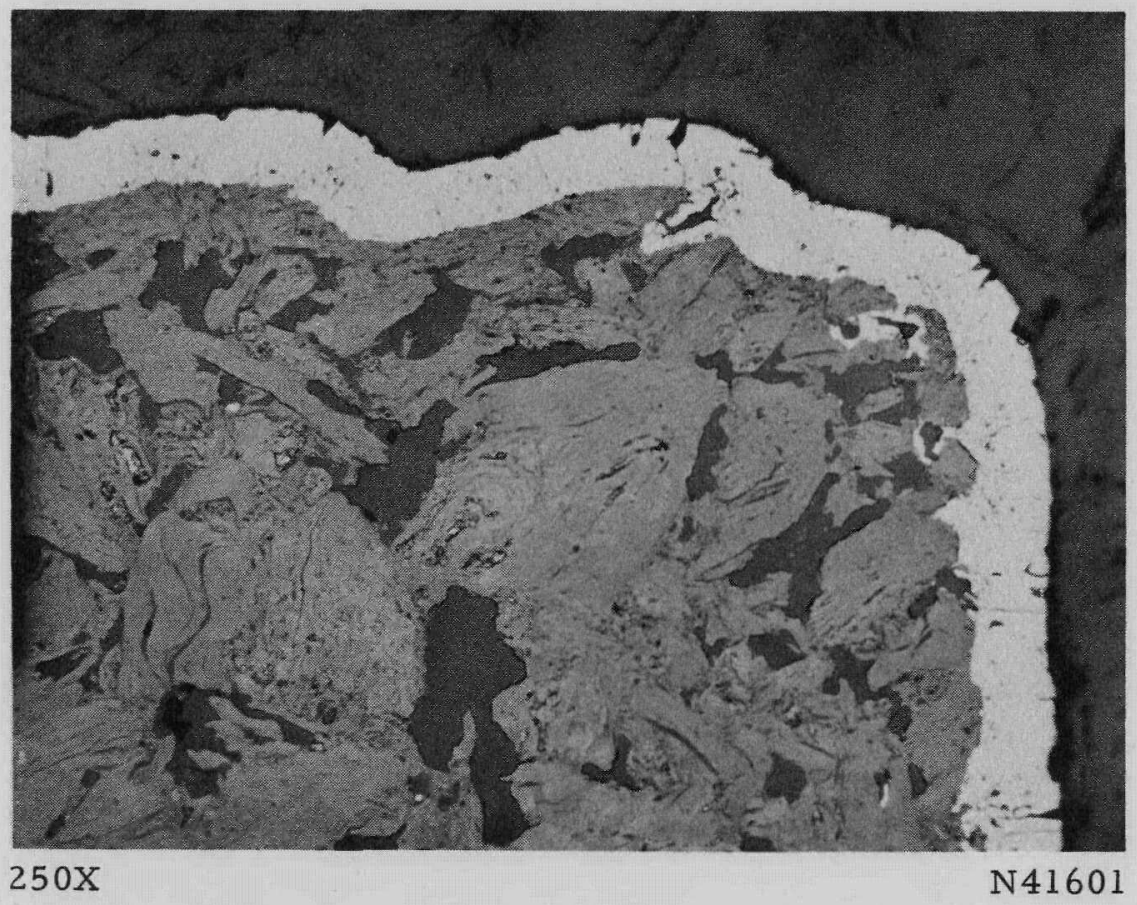

FIGURE 6. ZIRCONIUM CARBIDE COATING ON AT J GRAPHITE FORMED IN 30 MIN BY THERMAL DECOMPOSITION OF $\mathrm{ZrCl}_{4} \mathrm{AT}$ 1900 TO 2100 C AT 12 MM OF MERCURY

Run 12010-38.

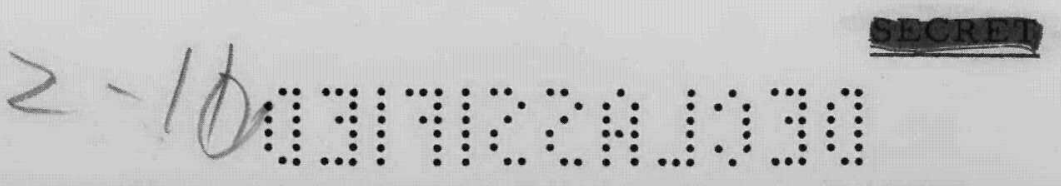


Attempts have been made to treat the data quantitatively, but with little success within the time limit imposed by justifying the effort. Even the treatment of the simplest situation is beyond the scope of this report, and the simple model is not entirely satisfactory.

It is possible, however, to obtain from thermodynamic considerations a semiquantitative picture of the range of pressure between metal deposition and carbide formation which is useful (see Appendix C).

On the assumption that dissociation has progressed to the point that the vapor at the limiting pressure consists solely of halogen atoms and molecules of the lower halide, it can be shown that the following relation holds:

$$
\log P_{M C} / P_{M}=\frac{-\Delta F M C}{(n-1) 2 \cdot 303 R T},
$$

where

$$
\begin{aligned}
& \mathrm{P}_{\mathrm{MC}}=\text { limiting pressure for carbide formation } \\
& \mathrm{P}_{\mathrm{M}}=\text { limiting pressure for metal formation } \\
& \Delta F_{M C}=\text { free energy of formation of the carbide } M C \\
& \mathrm{~T}=\text { temperature, } \mathrm{K} \\
& \mathrm{n}=\text { number of halogen atoms per atom of metal in } \\
& \text { the lower halide. }
\end{aligned}
$$

The carbides of interest in this work have free energies of formation of $-35 \pm 5$ kcal per mole(3) in the temperature range 1100 to $2000 \mathrm{C}$. Thus, if the trihalide is the stable gaseous species, the limiting pressures for metal and carbide formation should differ by $2.6 \mathrm{log}$ cycles at $1200 \mathrm{C}, 2.20 \mathrm{log}$ cycles at $1600 \mathrm{C}$, and $1.68 \mathrm{log}$ cycles at $2000 \mathrm{C}$. If the dihalide is the stable species, the above values are doubled.

It can be seen from Figures 1, 2, and 3 that the se differences are of the right order and that the convergence of the limiting pressures with increasing temperature is consistent with the analysis.

Another interesting relation derived from the simple picture described above is the fact that the slope of the $\log P_{M}$ versus $1 / T$ line gives directly (on multiplying by $-2.303 R)$ the heat of the reaction $M X_{2}(g)=M(s)+2 X(g)$ or one-half of the heat of reaction

$$
\mathrm{MX}_{3}(g)=M(s)+3 X(g)
$$

depending on whether the di- or trihalide is the existing stable species.

In the cases of tantalum and niobium, the slopes (or heats of dissociation) are greater for the chloride than for the bromide as would be predicted. The data for $\mathrm{ZrBr}_{4}$ are out of line with the chloride and iodide, however, and would make an interesting subject for study. On the basis of the simple analysis described above, this 
reversal indicates that, in the case of $\mathrm{ZrBr}_{4}$ decomposition, the lower valent stable species is the dihalide rather than the trihalide, the indicated form for chloride and iodide.

\section{Coating of Blowpipe Specimens}

The blowpipe test specimens to be coated with the carbides of niobium, tantalum, and zirconium consisted of tubes of ATJ graphite, $0.75 \mathrm{in}$. in OD, $0.25 \mathrm{in}$. in ID, and about 18 in. long, with a shouldered fitting at one end and a ball-and-socket fitting at the other. Initially, it was planned that only the inside bore be coated, but arrangements were made later to coat both the inside and outside surfaces.

The shape of these specimens makes them admirably suited to resistance heating. However, it was necessary to use long adaptors of similar cross section to reduce conductive heat loss from the ends of the specimens. Radiative heat loss was reduced by a shielding capsule consisting of two concentric tubes of graphite with crushed graphite in the annulus. The inner tube of the shielding capsule also served to direct the vapor flow around the specimens.

Figure 7 is a general view of the equipment used in most of the coating work * showing one unit ready for operation and the other partially assembled. Operation of the plating units can be understood by reference to Figure 8 . The entire assembly is contained in a water-cooled vacuum-tight tank, which can be outgassed and then subjected to an automatically controlled back pressure of inert gas. The internal assembly, consisting of a resistively heated graphite vaporizer, specimen and adaptors, and condenser is so arranged that the vaporizer takes the weight of the assembly when it rests on the bottom of the vacuum tank, and the specimen is free to expand on heating. Electrical connections to the vaporizer are made through the vacuum tank to the bottom of the vaporizer and to the stainless steel plate common to the vaporizer and the lower specimen adaptor. Connection to the top of the specimen is made at the plate holding the condenser. The heavy currents required are conducted to the electrode plates by water-cooled copper tubing which is coiled for flexibility. Separate power supplies are provided for the vaporizer and specimen as described in Appendix C.

Briefly, the operation consists of assembling the unit, inserting the charged vaporizer at the last moment before closure, evacuating the tank, setting the back pressure at a predetermined value, bringing the specimen up to temperature, and then heating the graphite vaporizer on a predetermined power schedule to vaporize the halide at an appropriate rate.

The proper balance of vapor flow through and around the specimen was achieved by optimizing the relative sizes of the axial and radial holes in the adaptors.

In the earlier work, when only the bore of the specimen was being coated, it was possible to measure the specimen temperature by sighting an optical pyrometer through the view port on the wall of the tank and a hole in the shielding capsule. When it became necessary to coat both the outside and inside of the specimens, the sight hole was closed and the Lavite insulating caps at the top and bottom of the capsule were made

*An earlier coating unit used in Runs 11661-50-1LM through 12416-47-19LF is described in Appendix B. 


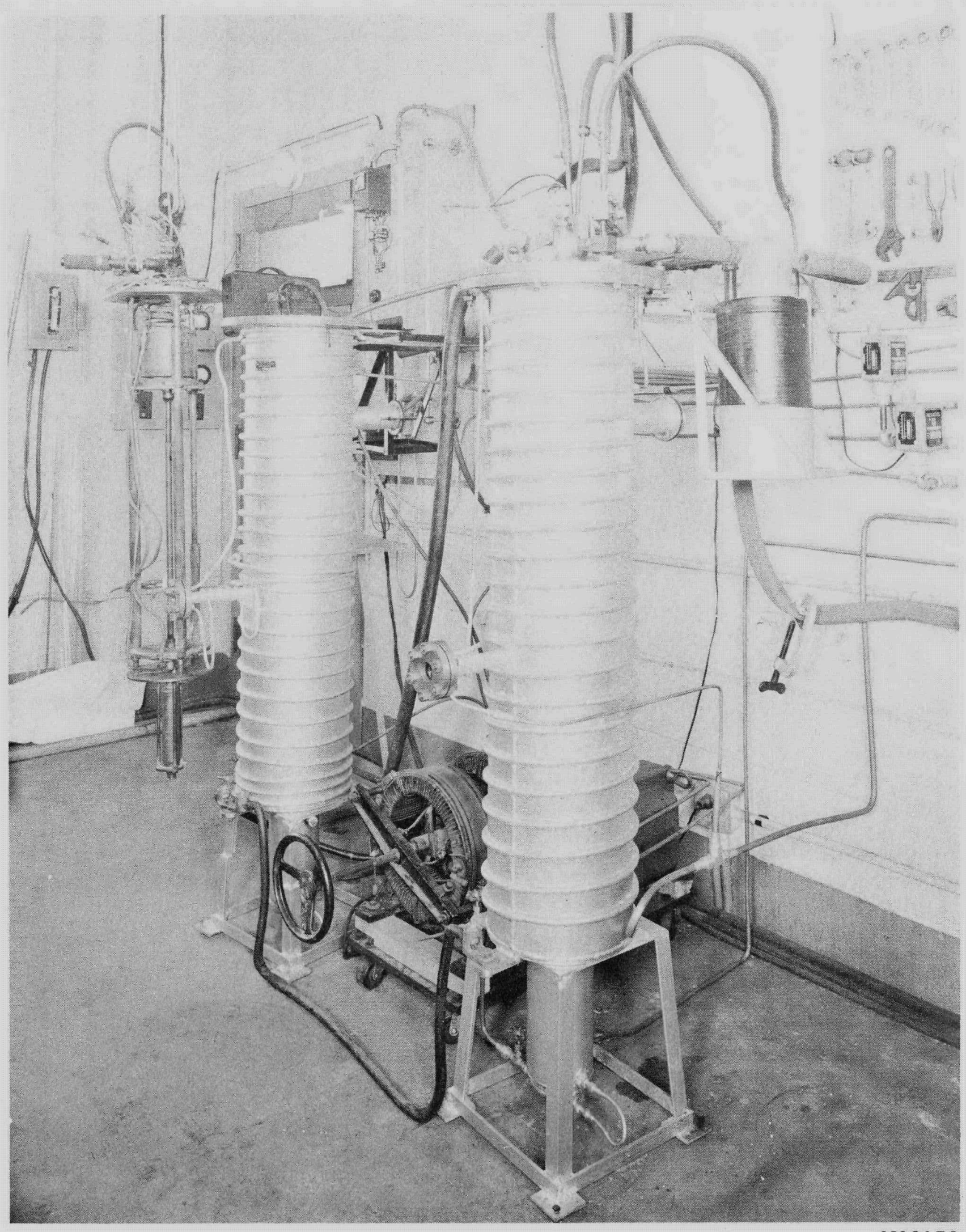

FIGURE 7. COATING EQUIPMENT FOR BLOW PIPE SPECIMENS

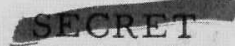

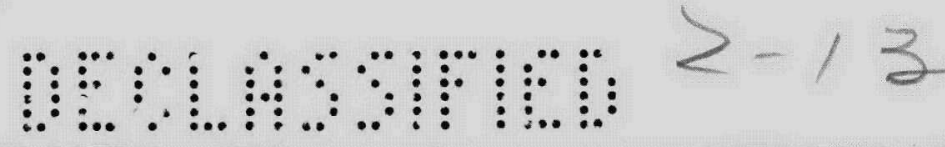


close fitting to minimize escape of vapor and to direct part of the vapor flow from the radial holes in the bottom adaptor around the specimen and into the radial holes in the top adaptor. Under these conditions, the specimen temperature was estimated by previously determined correlations with heating current and temperature of the outside wall of the insulating capsule.

Figure 9 shows an uncoated specimen, a set of adaptors, and specimens coated in $1 \mathrm{hr}$ at about $2000 \mathrm{C}$ with $\mathrm{NbC}, \mathrm{TaC}$, and $\mathrm{ZrC}$ from the chlorides at 50, 100, and $5 \mathrm{~mm}$ of mercury, respectively, the conditions finally adopted for coating most of the specimens.

Figures 10, 11, and 12 are reproductions of the X-radiographs of the above specimens. To obtain the metal-equivalent thickness of the coatings, the radiograph of the specimen was compared with that of a metal-foil step gage, by means of a densitometer. Figure 13 gives the corresponding densitometer traces showing metal-equivalent thicknesses of $7 \pm 1.5 \mathrm{mils}$ of niobium, $3 \pm 0.7 \mathrm{mils}$ of tantalum, and $2 \pm 0.5 \mathrm{mils}$ of zirconium.

Since the ratios of the densities of metal(4) to monocarbide(5) for niobium, tantalum, and zirconium are $1.092,1.14$, and 1.01 , respectively, the carbide thicknesses would be a little greater than the values given above. The factors influencing the accuracy of this method of measurement have not been fully evaluated. However, in the few cases where the coating thickness was also measured by microscopic examination, the agreement was within 25 per cent.

The gradient in coating thickness is due to temperature gradients in the specimen. Contact resistance at the junction of the adaptor and specimen may account for the thicker coating at the ends. Other variations are attributable to specimen inhomogeneity. The resistance per unit length as a function of distance along the specimen axis was measured for all specimens prior to coating. Those showing greater than \pm 10 per cent variation were discarded.

Better temperature compensation at the ends of the specimen may be obtainable by further alteration of the adaptor geometry.

Figures 14, 15, and 16 are photomicrographs of typical cross sections showing the continuity and general structure of the blowpipe-specimen coatings. The difference in appearance of the coatings shown is significant. The outward appearance of the specimens is consistent with the microstructure, in that $\mathrm{NbC}$ - and $\mathrm{ZrC}$-coated specimens are smooth and bright* while the $\mathrm{TaC}$ coatings are a matte-gold, indicating a rough surface.

It can be seen from the phase diagrams in Figure 17 that at coating temperatures of 2000-2200 C, $\mathrm{ZrC}$ and $\mathrm{NbC}$ coatings(6) are formed above the solidus in the metalcarbide system, whereas, $\mathrm{TaC}$ is formed below the solidus (7). It is probable that $\mathrm{Z}$ rC and $\mathrm{NbC}$ form by crystallization from a liquid film at the outer surface of the coating, leading to a denser carbide.

It is interesting to note that X-ray diffraction measurements show only the monocarbides in the blowpipe-specimen coatings.

* ZrC is silvery. NbC is silvery with a pink tinge. 


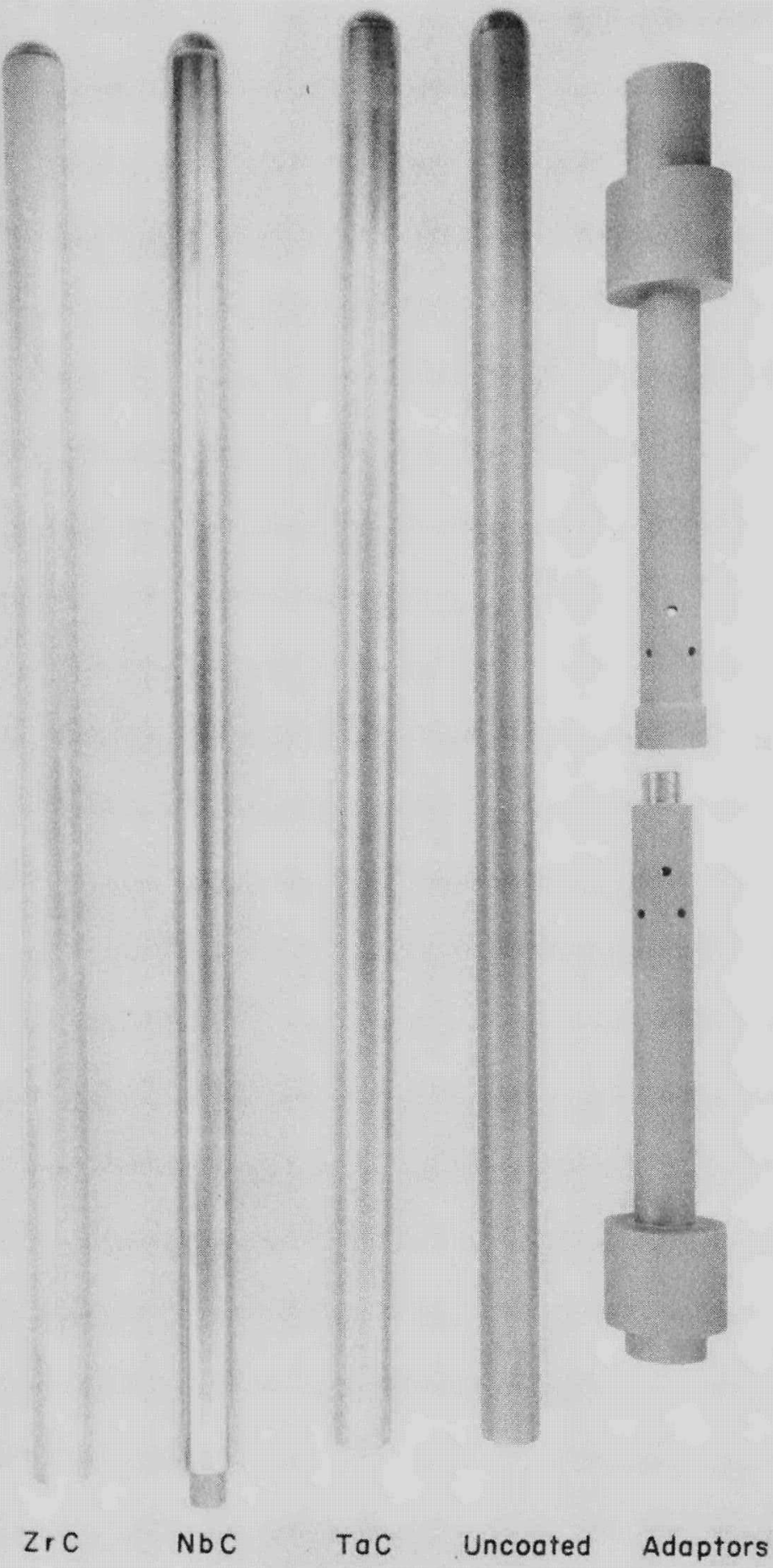

FIGURE 9. COATED AND UNCOATED BLOWPIPE SPECIMENS AND A SET OF ADAPTORS

TaC coated, Run 13331-19-75LF.

NbC coated, Run 13331-28-78LM.

$\mathrm{ZrC}$ coated, Run 13331-73-93LF.

SECRET

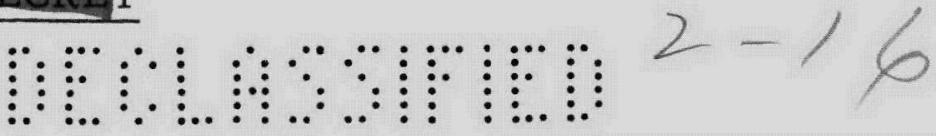





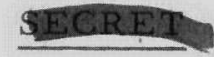

23

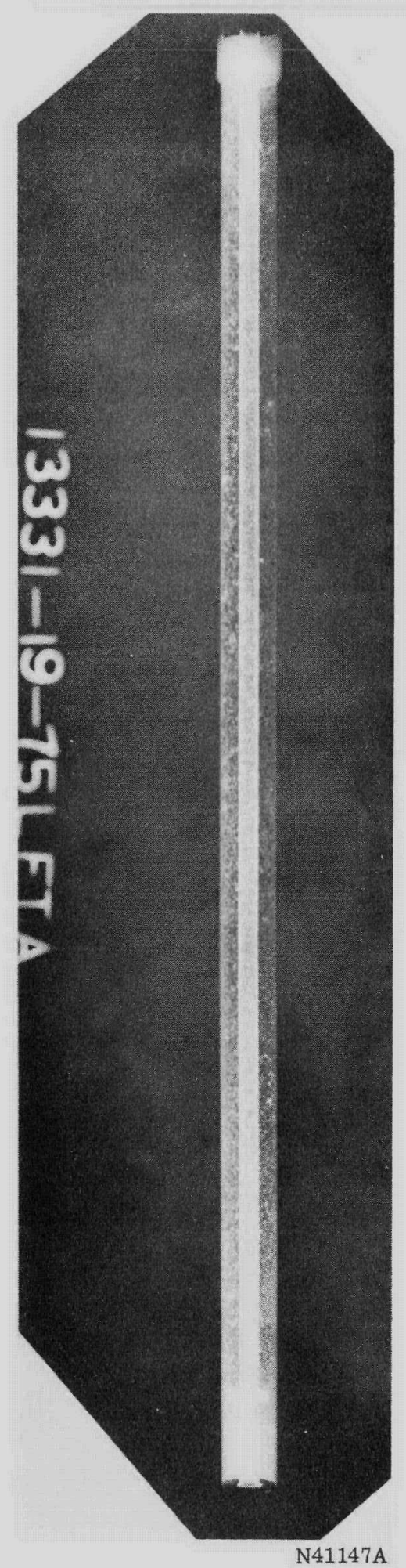

FIGURE 11. RADIOGRAPH OF TaC $\prec$ COATED SPECIMEN

Run 13331-19-75LF. Coated by thermal decomposition of $\mathrm{TaCl}_{5}$.

Note: Radiograph taken with portions of the adaptors adhering to the ends of the specimen.

SECRET

आா। 


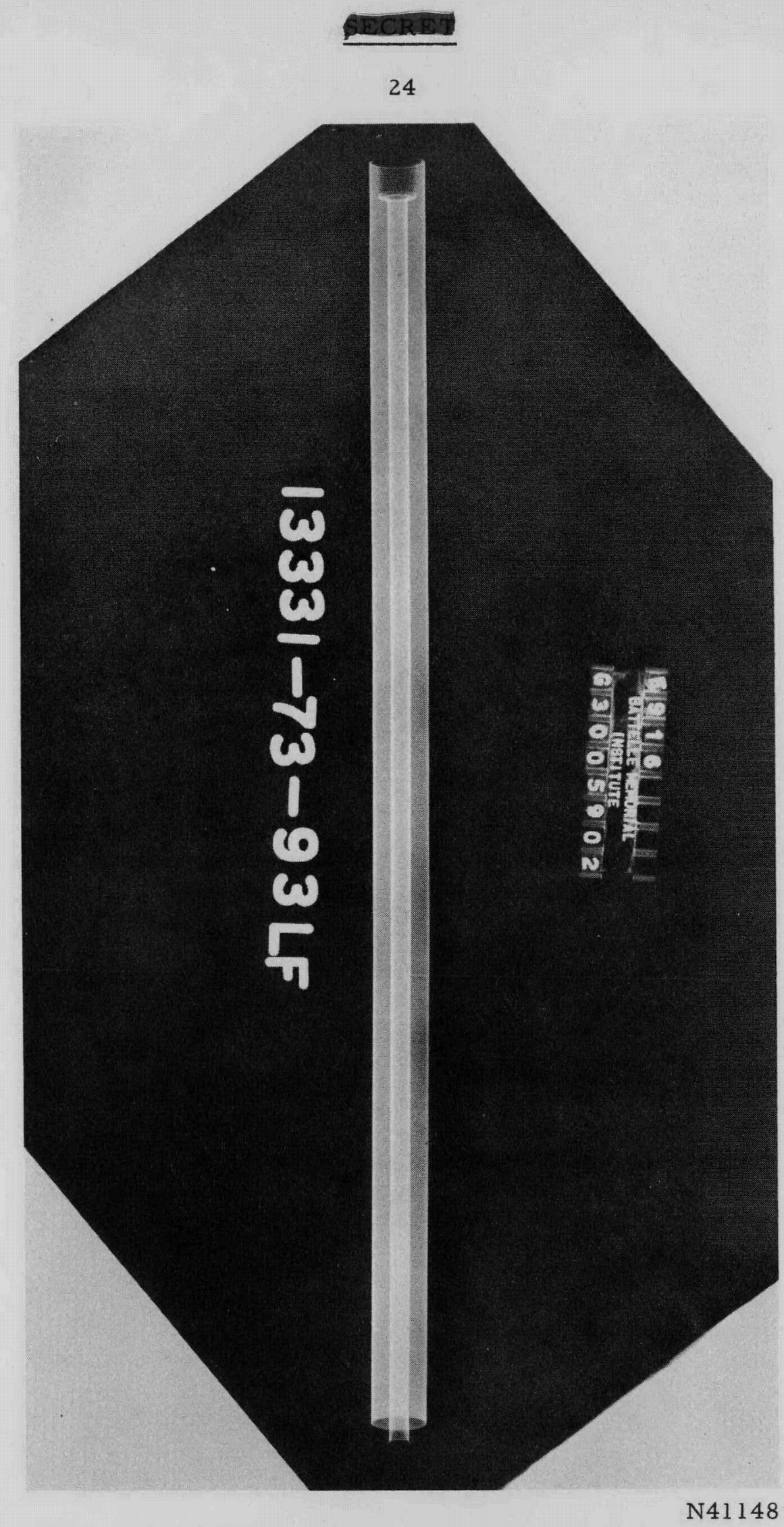

FIGURE 12. RADIOGRAPH OF ZrC-COATED SPECIMEN Run 13331-73-93LF. Coated by the thermal decomposition of $\mathrm{ZrCl}_{4}$.
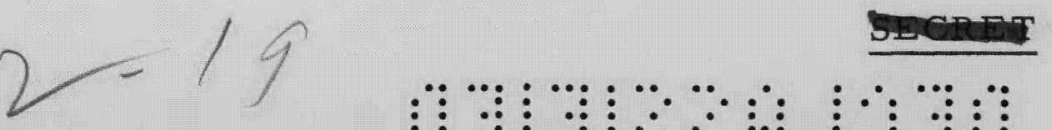

艾: 


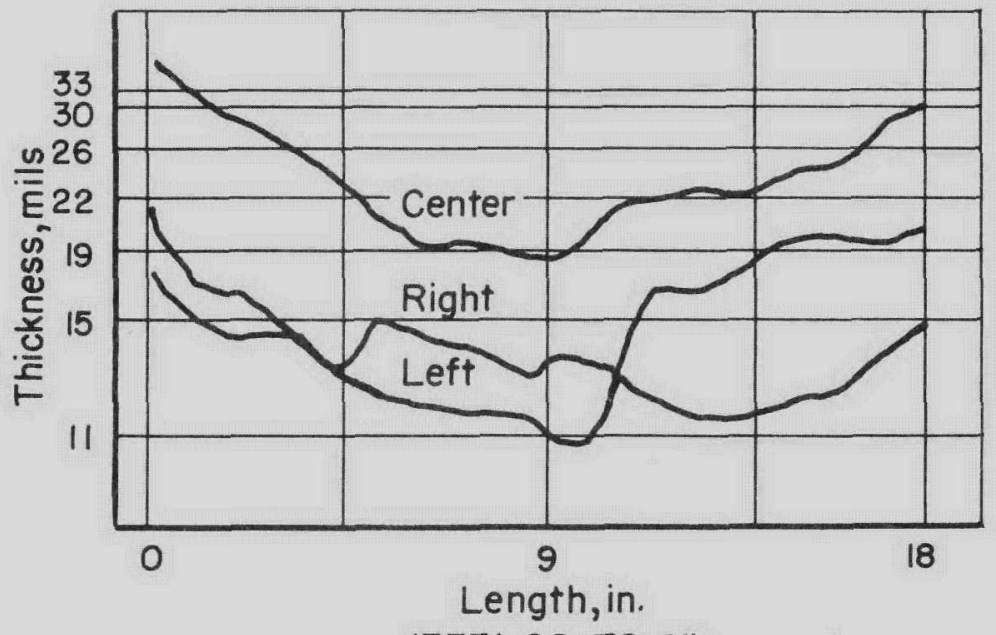

13331-28-78-Nb
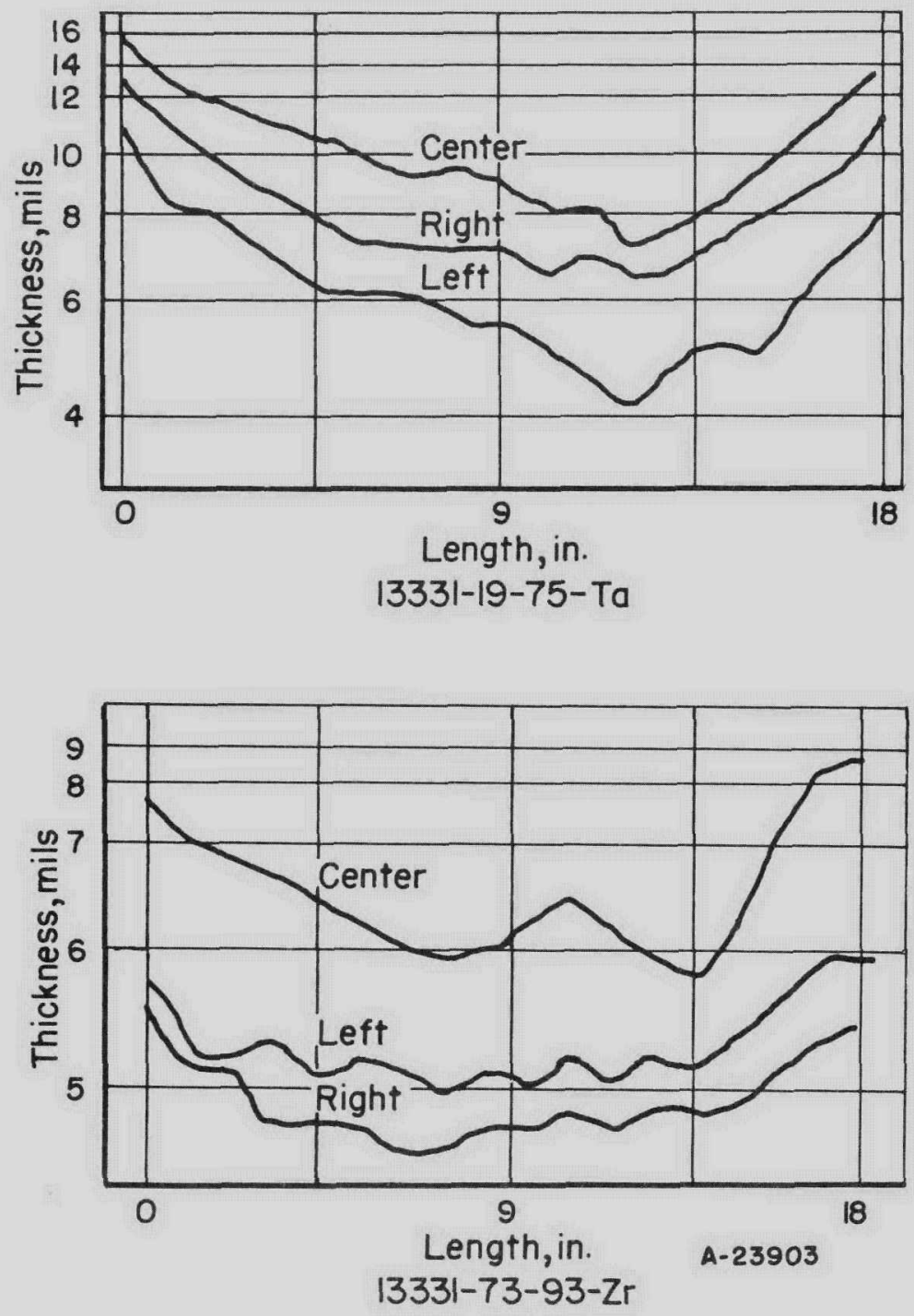

FIGURE 13. DENSITOMETER TRACES

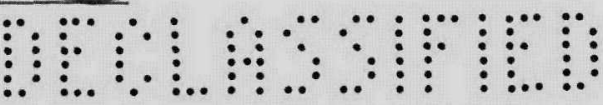




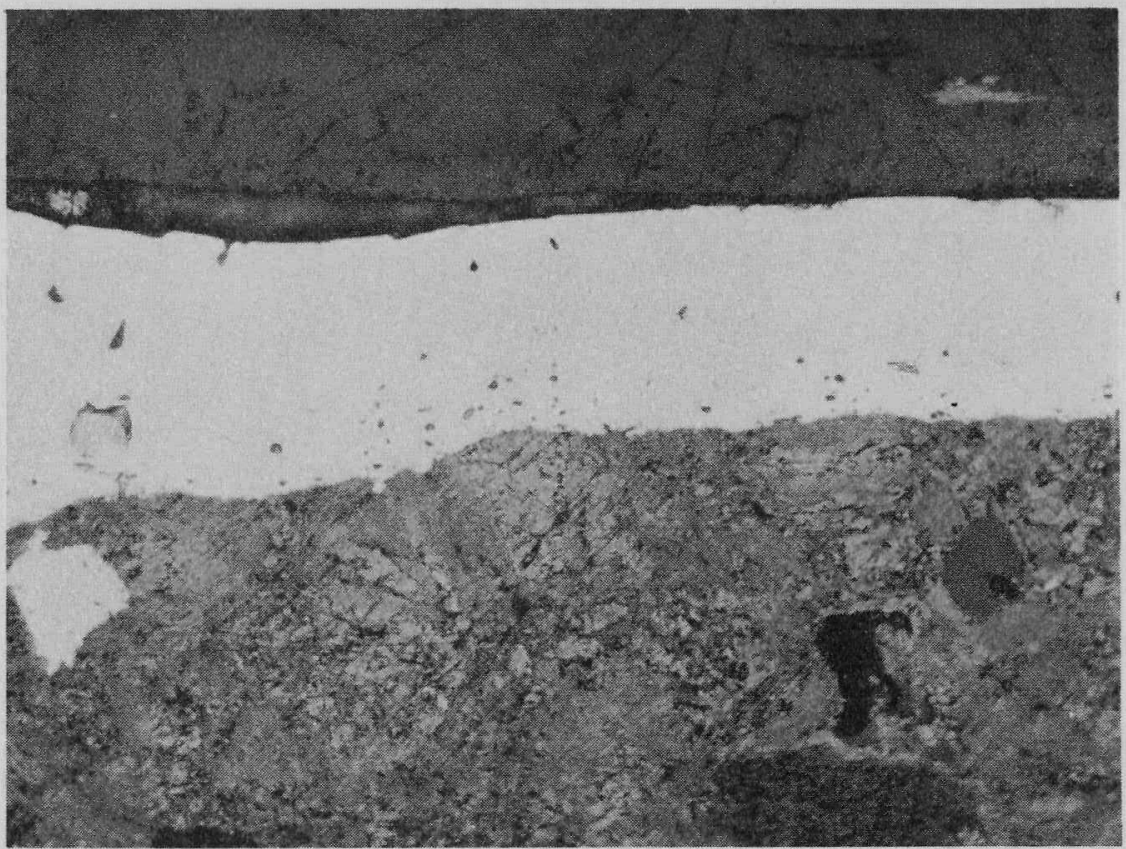

FIGURE 14. NIOBIUM CARBIDE COATING ON ATJ GRAPHITE FORMED BY THERMAL DECOMPOSITION OF NIOBIUM PENTACHLORIDE

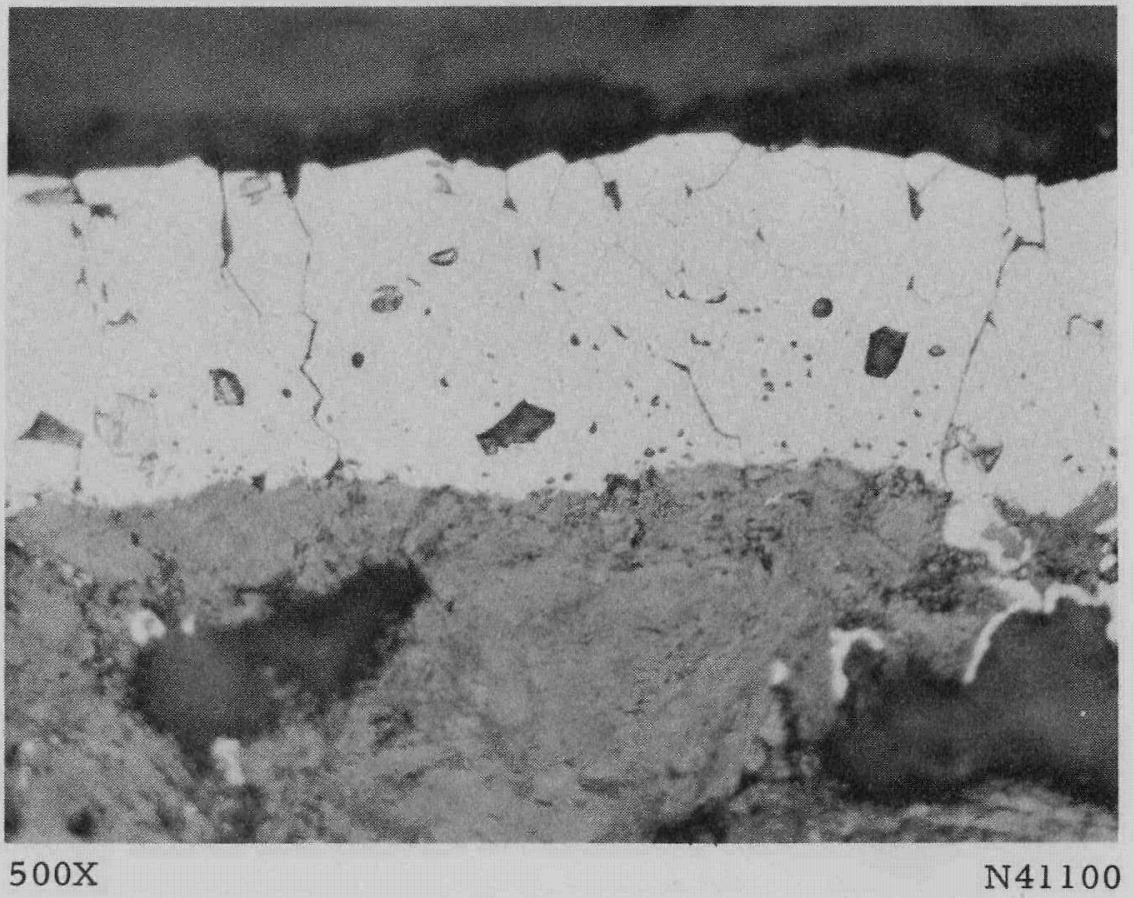

FIGURE 15. TANTALUM CARBIDE COATING ON ATJ GRAPHITE FORMED BY THERMAL DECOMPOSITION OF TANTALUM PENTACHLORIDE 

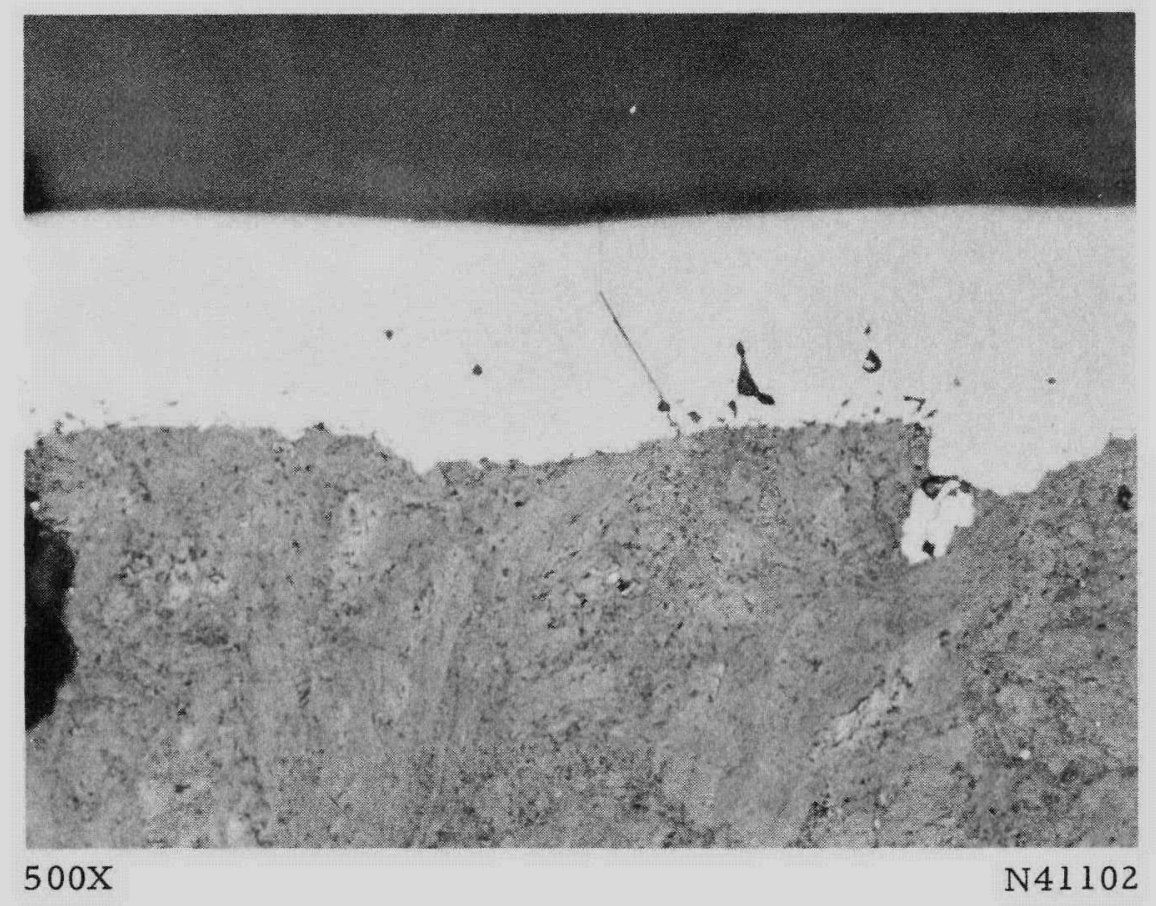

FIGURE 16. ZIRCONIUM CARBIDE COATING ON AT J GRAPHITE FORMED BY THERMAL DECOMPOSITION OF ZIRCONIUM TETRACHLORIDE 

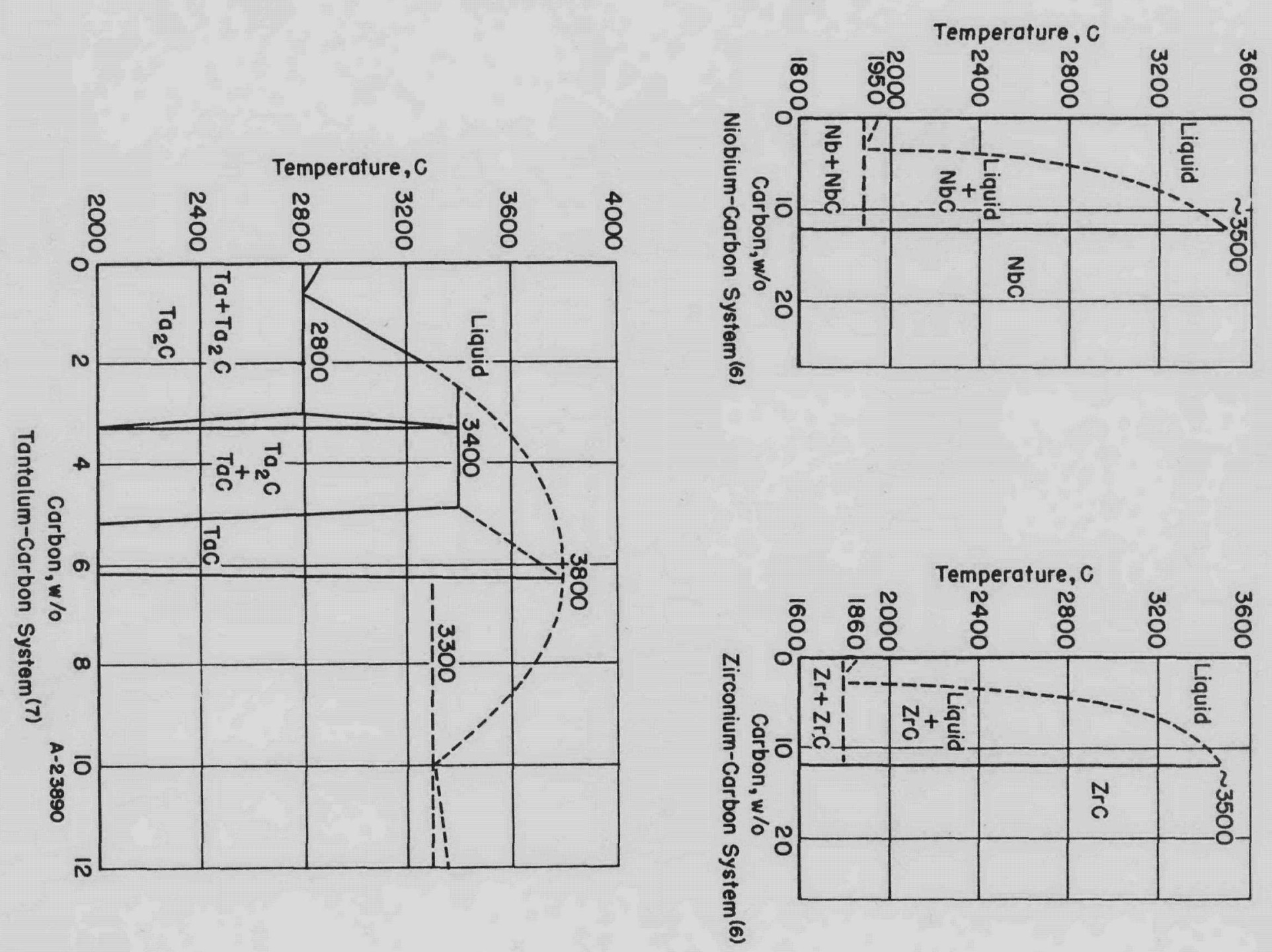
When the proper coating conditions were determined and the equipment had been developed, specimens were routinely coated at a rate of two or three per day.

A total of 99 useful specimens was coated with the three carbides in various thicknesses ranging from 0.5 to 20 mils.

\section{Coating of Uranium-Impregnated Specimens}

Uranium-impregnated ATJ graphite specimens were coated to test the effect of the presence of uranium on the resultant coating and to determine the extent to which uranium is leached from the specimens in the coating process.

Six rods of ATJ graphite, 3/32 in. in diameter, were sent to UCRL where they were solution impregnated with about $7 \mathrm{w} / 0$ uranium and fired to form the carbide. The specimens were coated as received in the apparatus described in Appendix A. Vaporization of the halide was brought to a steady state before the specimen was heated to the coating temperature of 2000 to $2070 \mathrm{C}$.

In three cases, the halide condensate from the coating operation was collected and analyzed for total uranium to determine the extent of leaching.

Table 1 gives the coating conditions and results.

TABLE 1. COATING OF URANIUM-IMPREGNATED SPECIMENS

\begin{tabular}{|c|c|c|c|c|c|}
\hline \multirow[b]{2}{*}{ Specimen } & \multirow[b]{2}{*}{ Halide } & \multirow{2}{*}{$\begin{array}{c}\text { Pressure, } \\
\text { mm of mercury }\end{array}$} & \multicolumn{2}{|c|}{ Uranium Content, $\mathrm{mg}$} & \multirow{2}{*}{$\begin{array}{l}\text { Loss, } \\
\text { per cent }\end{array}$} \\
\hline & & & Initial $(a)$ & Condensate & \\
\hline$L-1$ & $\mathrm{Z} \mathrm{rCl}_{4}$ & 6.0 & - & -- & - \\
\hline$L-2$ & $\mathrm{ZrCl}_{4}$ & 5.0 & 58 & 37.2 & 64 \\
\hline $\mathrm{L}-3$ & $\mathrm{NbCl}_{5}$ & 49.5 & 56 & 37.9 & 67.5 \\
\hline $\mathrm{L}-4$ & $\mathrm{NbCl}_{5}$ & 50.0 & -- & -- & -- \\
\hline$L-5$ & $\mathrm{TaCl}_{5}$ & 106.5 & 53 & 50.4 & 95 \\
\hline L-6 & $\mathrm{TaCl}_{5}$ & 102.5 & - & -- & -- \\
\hline
\end{tabular}

(a) UCRL analysis.

Table 2 gives the results of $\mathrm{X}$-ray diffraction examination of the coatings. 
TABLE 2. CONSTITUTION OF COATINGS ON URANIUMIMPREGNATED GRAPHITE

\begin{tabular}{|c|c|c|c|c|}
\hline Specimen & Phase & Intensity & Parameter, A & Remarks \\
\hline L-2 & $\begin{array}{l}\mathrm{Zr} \\
\mathrm{ZrC}\end{array}$ & $\begin{array}{l}\text { Faint } \\
\text { Strong }\end{array}$ & $4.692(a)$ & -- \\
\hline L-4 & $\begin{array}{l}\mathrm{NbC} \\
\mathrm{Cubic} \\
\mathrm{Nb}_{2} \mathrm{C} \text { (?) }\end{array}$ & $\begin{array}{l}\text { Strong } \\
\text { Medium faint } \\
\text { Medium faint }\end{array}$ & $\begin{array}{l}4.467^{(a)} \\
4.45\end{array}$ & Carbon deficient? \\
\hline L-5 & $\begin{array}{l}\mathrm{TaC} \\
\mathrm{TaC} \\
\mathrm{Ta}_{2} \mathrm{C}\end{array}$ & $\begin{array}{l}\text { Very strong } \\
\text { Medium faint } \\
\text { Very faint }\end{array}$ & $\begin{array}{l}4.55(a) \\
4.40\end{array}$ & Carbon deficient? \\
\hline
\end{tabular}

(a) Schwarzkopf ${ }^{(5)}$ gives a $=4.685,4.46$, and $4.55 \mathrm{~A}$ for face-centered-cubic $\mathrm{ZrC}, \mathrm{NbC}$, and TaC, respectively.

Figures 18, 19, and 20 compare the coatings with samples obtained on unimpregnated graphite (previously pictured in Figures 14, 15, and 16).

Comparison of the photomicrographs reveals the similarity of the coatings, with a somewhat greater concentration of voids and fissures present in the coatings of the impregnated specimens. However, other coatings such as those pictured in Figures 4 , 5 , and 6 show varying concentrations of voids. Thus, it is not possible, without further study under controlled conditions, to assess accurately the effect of the presence of uranium on the resultant coating.

The loss of uranium, presumably by the reduction of the halide vapors, is the most significant result of these experiments. Some leaching was expected. However, loss of this magnitude was surprising. Since it is understood that the uranium concentration was greatest at the surface of these solution-impregnated samples, the leaching effect would be expected to be more drastic here than with graphite, which is homogeneously loaded with uranium during its manufacture.

The leaching of uranium from uniformly loaded graphite was tested with samples resulting from longitudinally quartering a tube supplied by the Los Alamos Scientific Laboratory. The specimens were in the form of rods of roughly triangular cross section, about $3 / 32$ in. on a side.

The uranium content of one of the quarters, $7.2 \mathrm{w} / \mathrm{o}$, was taken as the original loading of the other three. Coating conditions and results are given in Table 3 . The coating thickness was not measured in this series of experiments. However, the coating appeared to be normal and about 2 to 5 mils in thickness. 

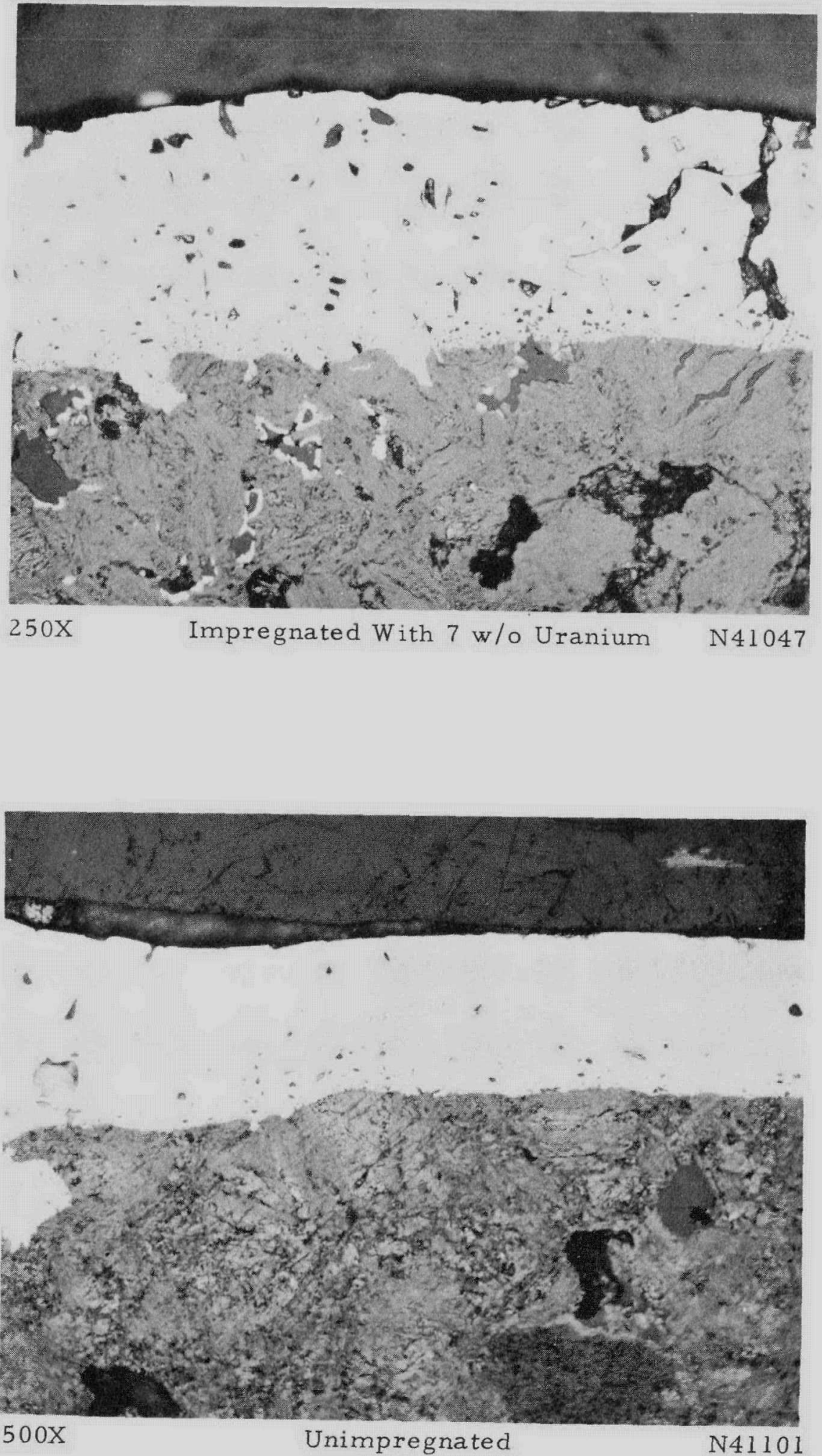

FIGURE 18. NbC COATINGS ON ATJ GRAPHITE 

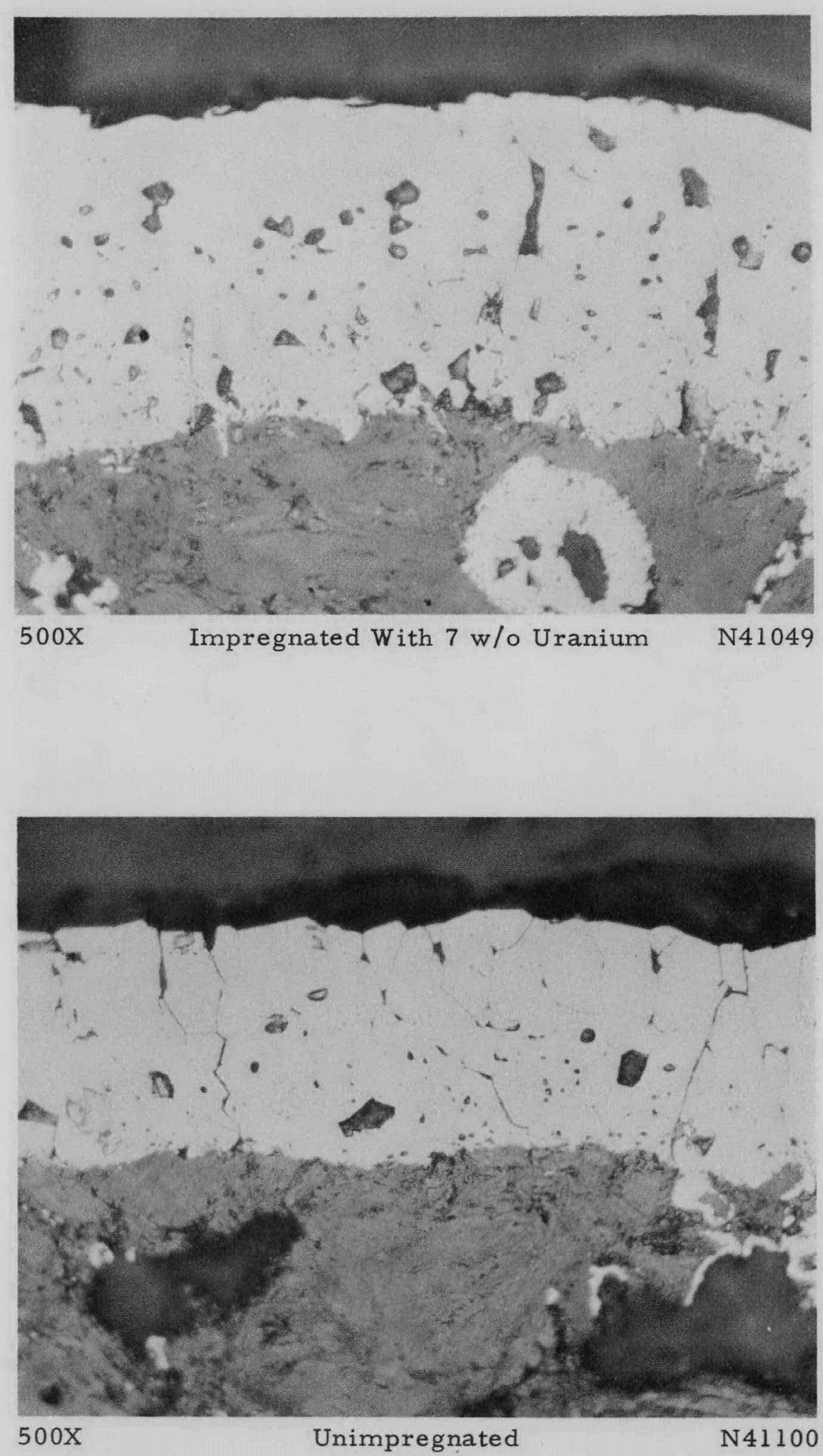

FIGURE 19. TaC COATINGS ON ATJ GRAPHITE
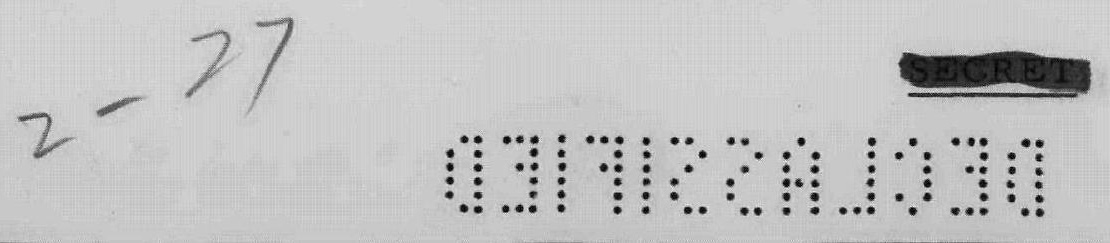

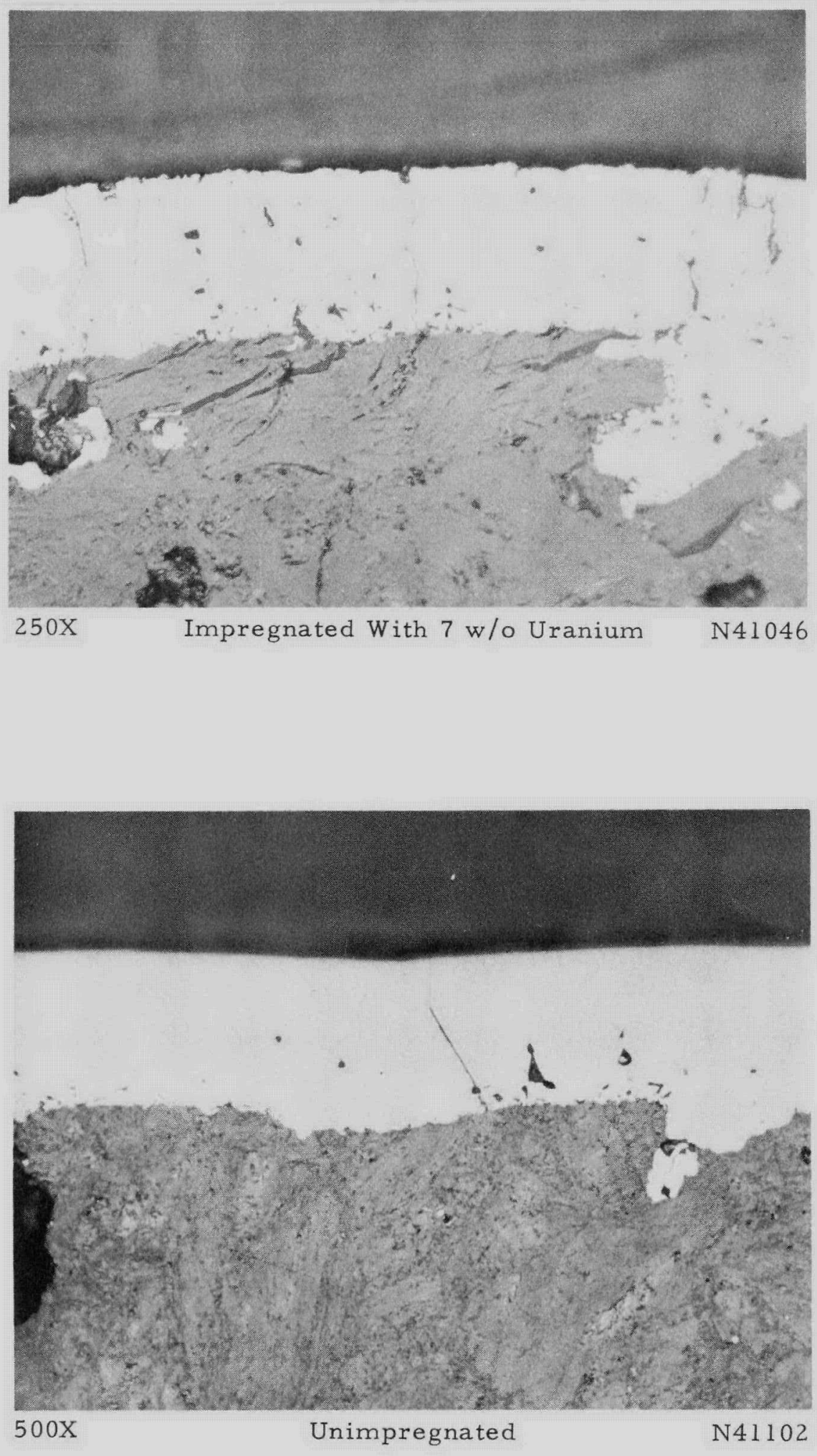

FIGURE 20. ZrC COATINGS ON ATJ GRAPHITE

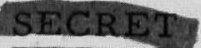

: 


\section{TABLE 3. LEACHING OF UNIFORMLY LOADED GRAPHITE}

\begin{tabular}{ccccccc}
\hline \hline Specimen & Halide & $\begin{array}{c}\text { Temperature, } \\
\text { C }\end{array}$ & $\begin{array}{c}\text { Time, } \\
\text { hr }\end{array}$ & $\begin{array}{c}\text { Pressure, } \\
\text { mm of } \\
\text { mercury }\end{array}$ & $\begin{array}{c}\text { Residual Ura- } \\
\text { nium Content(a), } \\
\text { weight per cent }\end{array}$ & $\begin{array}{c}\text { Loss, } \\
\text { per cent }\end{array}$ \\
\hline A & $\mathrm{ZrCl}_{4}$ & 1950 & 1 & 5 & 4.1 & 43 \\
B & $\mathrm{NbCl}_{5}$ & 1950 & 1 & 50 & 3.7 & 48.5 \\
$\mathrm{C}$ & $\mathrm{NbCl}_{5}$ & 1950 & 1 & 50 & 1.75 & 75.0 \\
\hline \hline
\end{tabular}

(a) Analysis of the heated section of the rod.

As expected, the loss of uranium from homogeneously loaded graphite was, in general, less than from surface-impregnated material. However, the lack of agreement between the results of the Runs, B and C, under presumably identical conditions deserves further investigation.

Since the leaching is a surface phenomenon, presumably controlled by the rate of diffusion of uranium through the graphite, the net loss would be expected to decrease as the specimen size is increased. It may also be possible to decrease the loss of uranium by "buffering" the coating vapor feed with an appropriate concentration of uranium halide.

\section{Diffusion of Carbon in Carbides}

As was noted above, coating of the blowpipe specimens was carried out under conditions designed to control the over-all rate by the rate of diffusion of carbon through the carbide. Ideally, it should be possible to obtain diffusion constants from the rate of coating formation. However, it is possible to obtain only lower limiting values from the coating data since, although the time-temperature schedule of heating the vaporizer was known in each case, it was not certain when vaporization of the halide under appropriate conditions had started and stopped. Moreover, to the extent that other factors (such as mass-transfer at the vapor-solid interface) may have effected partial control, the coating data give only minimum values for the diffusion rate.

Thus, after the limiting pressures for metal and carbide formation had been determined toward the end of the contract period, it was decided to attempt diffusion measurements in the coating equipment for small rod specimens (see Appendix A). In this equipment, vaporization can be initiated and the specimen heated and cooled quickly so that the time at coating temperature is known. Moreover, it was found that, with suitable precautions, it was possible to follow the progress of the coating by monitoring the electrical conductivity of the resistively heated specimen. 
If diffusion of carbon through the carbide is actually controlling, the coating rate follows a parabolic function:

$$
d=k \sqrt{t}
$$

where $d$ is the coating thickness (assuming a plane surface), $k$ is a constant,and $t$ is the time. If the over-all rate were controlled by mass transfer at the vapor interface, the rate would be linear with time. Thus, it is assumed that, if the coating rate is parabolic, it is characteristic of the diffusion of carbon through the carbide.*

It can be shown $(8)$ that diffusion for cases of this type occurs according to the relation

$$
y=\frac{d}{2 \sqrt{D t}}
$$

where $y$ is a complex function of the concentration gradient through which diffusion takes place. $D$ is the coefficient of diffusion in the fundamental diffusion equation:

$$
\frac{d C}{d t}=\frac{\partial}{\partial x}\left(D \frac{\partial C}{\partial x}\right)
$$

Since no data are available on the solubilities of carbon in $\mathrm{NbC}, \mathrm{TaC}$, and $\mathrm{ZrC}$ with which to evaluate y and, therefore, D explicitly, it is necessary to use the equation in the form: $D y^{2}=\frac{d^{2}}{4 t}$ for the interpretation of the data. Now, if the concentration gradient does not vary with temperature, a plot of $\log \mathrm{Dy}^{2}$ versus $1 / \mathrm{T}$ will give the true value of the activation energy for diffusion. Moreover, if it can be assumed that the same carbon concentration gradient exists in the coating process as in the attack of the coated specimen, for example by hydrogen reacting with the diffusing carbon, the diffusion data from the coating experiments can be applied directly to the corrosion problem.

\section{Experimental Work}

The principal difficulty with obtaining the required data in the small coating apparatus was that of providing vapor-flow rates sufficiently high to avoid mass-transfer control at the vapor-solid interface and permit the observation of solid-solid diffusion control. By using a large supply of halide in the vaporizer section, a high heat input to the vaporizer, and by eliminating the back pressure (evacuating the condenser section of the tube), it was possible to obtain parabolic growth curves of the type shown in Figure 21.** At lower heat inputs to the vaporizer, lower linear coating rates were obtained.

\footnotetext{
*It is also possible to interpret the data on the basis of diffusion of the metal through the carbide. However, since the carbon is the more mobile, it is considered to be the diffusing species.

- The points along these curves were obtained by combining the coating thickness measured at the end of a run with conductıvity measurements during the run. Electrical leads were provided to measure the voltage drop across the heated section of the specimen carrying a known current. A quartz-wool plug was used to prevent entrainment of solid halide particles.
}

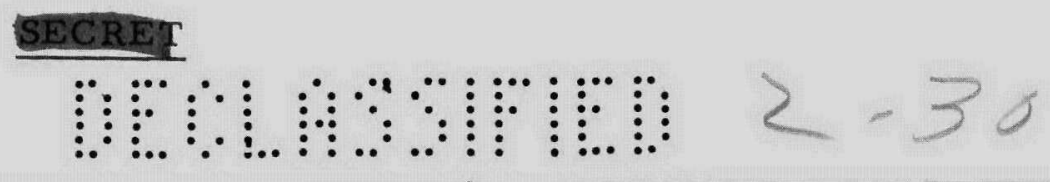




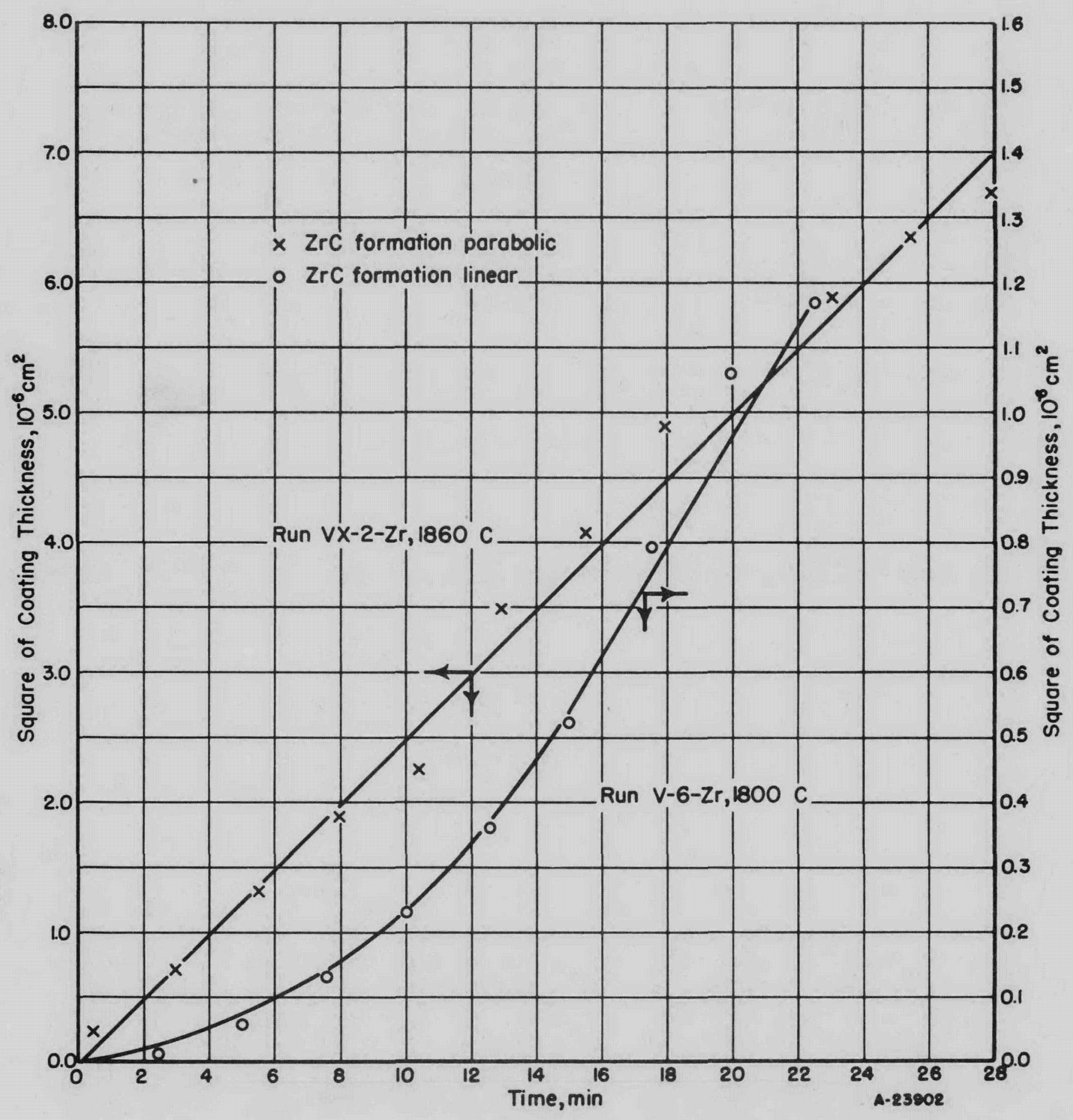

FIGURE 21. ZrC COATING THICKNESS AS A FUNCTION OF TIME

$2-3^{\prime}$

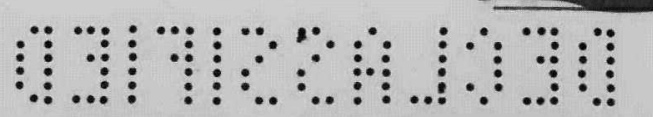




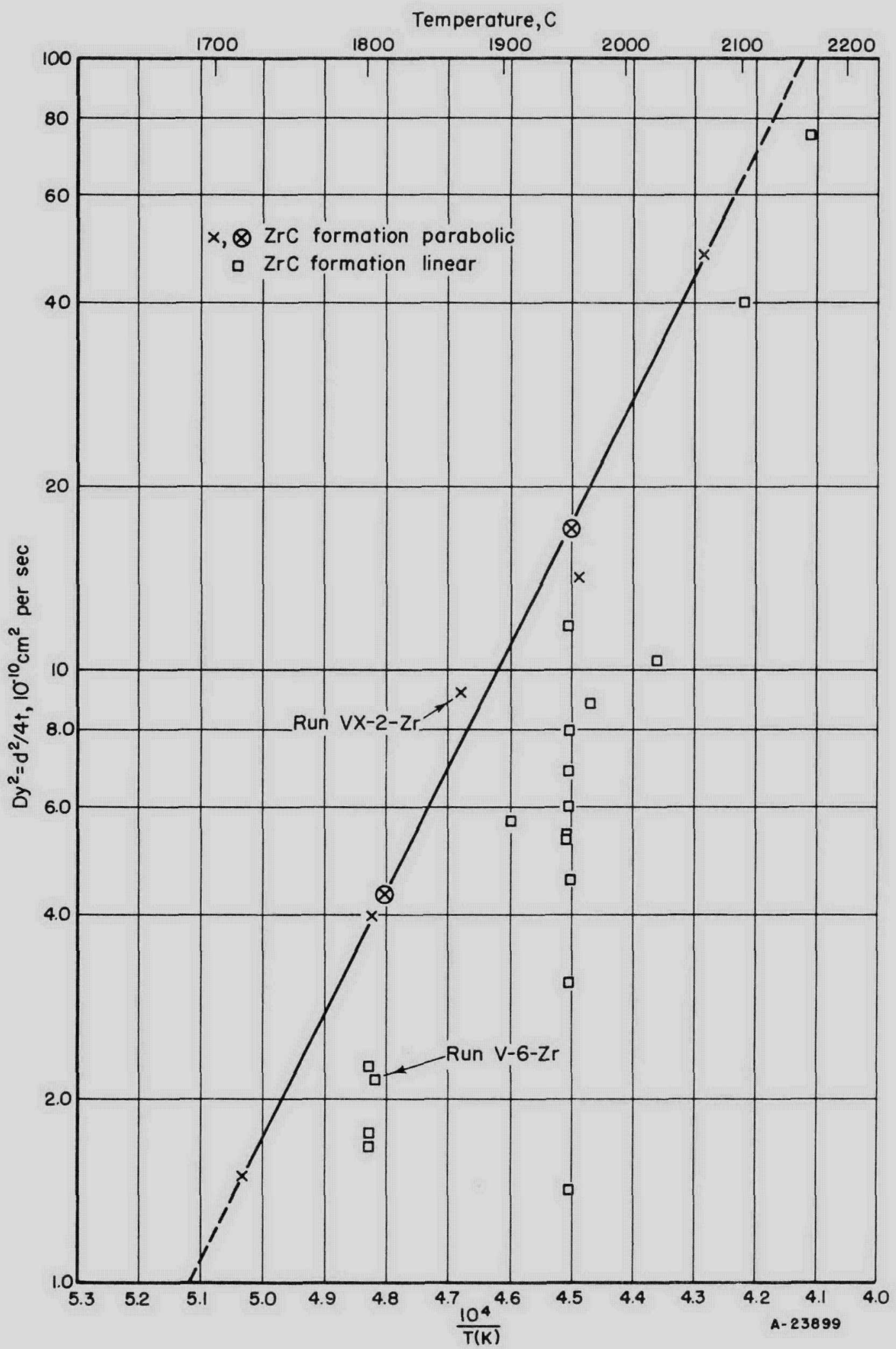

FIGURE 22. ZrC COATING RATE AS A FUNCTION OF TEMPERATURE 
Figure 22 shows the coating rate as a function of temperature for the formation of $\mathrm{ZrC}$ by the thermal decomposition of $\mathrm{ZrCl}_{4}$. As would be expected, the linear, or vapor-flow-controlled rates are all below the parabolic rates.

It appeared that, at the high vapor-flow rates, and despite the evacuation of the condenser section of the tube, the pressure below the vapor barrier and in the region of the specimen was in the range favorable to carbide formation, but unfavorable to metal deposition, e.g., above $0.8 \mathrm{~mm}$ of mercury at $2100 \mathrm{C}$. This was checked by making two runs with a back pressure of $2 \mathrm{~mm}$ which is well within the desired range (see Figure 3). The results (encircled points in Figure 22) confirmed those obtained with the condenser section evacuated to promote maximum vapor flow.

The equation for the rate of $\mathrm{ZrC}$ formation, which presumably represents the rate of diffusion of carbon through the carbide is:

$$
\log _{10} \mathrm{Dy}^{2}=-\frac{20,000}{\mathrm{~T}}+0.24
$$

The indicated activation energy of $91.5 \mathrm{kcal}$ fall s between the values $108 \mathrm{kcal}$ and 59 kcal given respectively by Andrews and Dushman (9) and by Pirani and Sandor (10) for the diffusion of carbon through $\mathrm{W}_{2} \mathrm{C}$. A discussion of the discrepancy between the values for $W_{2} C$ is beyond the scope of this report.

Investigation of the corresponding niobium system was inconclusive at the end of the contract period. Several anomalous results were obtained, and it is not certain that the rates of coating formation were controlled by the diffusion of carbon through the carbide. Additional research would be required to obtain reliable information on the diffusion of carbon through $\mathrm{NbC}$.

\section{ACKNOW LEDGMENT}

From time to time, during the course of this research, Battelle staff members other than the authors have given valuable aid which is gratefully acknowledged. J. A. Hoess, H. F. Carlton, E. A. Beidler, D. G. Black, and J. F. Hannah contributed to the final design, construction, and operation of the coating equipment, while Miss V. M. Sheipline aided in the limiting-pressure determinations.

\section{REFERENCES}

(1) Powell, C. F., Campbell, I. E., and Gonser, B. W., Vapor Plating, John Wiley \& Sons, New York (1955).

(2) Van Arkel, A. E., Metallwirtschaft, 13, 405-408 (1934).

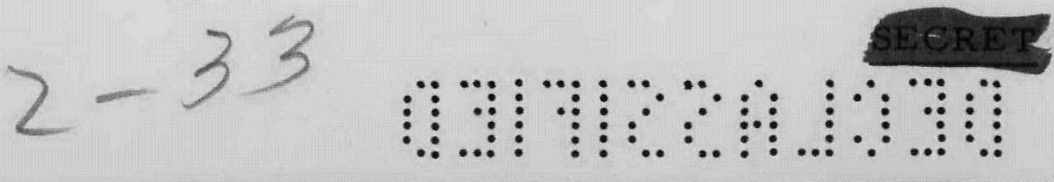




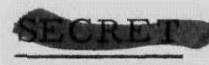

39 and 40

(3) Brewer, Leo, and Krikorian, Oscar, UCRL-2888.

(4) Van Arkel, C. E., Reine Metalle, Julius Springer, Berlin (1939).

(5) Schwarzkopf, Paul, Refractory Hard Metals, The MacMillan Company, New York (1953).

(6) Goldschmidt, H. J., J. Iron Steel Inst., 160, 345 (1948).

(7) Ellinger, F. H., Trans. ASM, 31, 89 (1943).

(8) Crank, J., The Mathematics of Diffusion, Oxford, Clarendon Press (1956).

(9) Andrews, M. R., and Dushman, S., J. Phys. Chem., 29, 462 (1925).

(10) Pirani, M., and Sandor, J., J. Inst. Metals, 73, 385 (1947).

JMB:C JI:DP L: LFP:IEC / ims 
…...:

¿...:.

…....

....:.:

$\because \because$

$\because \because$

:.:.

$\vdots \ldots .$.

$\therefore \ldots$

$\vdots \ldots:$ :

$\therefore . . .$. 
APPENDIX A

APPARATUS AND PROCEDURE FOR LIMITING-PRESSURE DETERMINATIONS

The apparatus consisted of two identical units mounted side by side, utilizing the same electrical system, vacuum source, surge tank, and gettering furnace. The units were operated alternately. Filament temperatures were measured with an optical pyrometer.

Figure A-1 shows Unit 1 in operation. Figure A-2 shows Unit 2, with a hot-wire filament, being evacuated prior to charging with halide. Figure A-3 shows the electrode assembly with a carbon rod. The corresponding electrode assembly for metal deposition can be seen in the reaction tube in Figure A-2.

Since the vacuum requirements for the apparatus were nominal, a rubber-stopper closure was used for simplicity and flexibility. However, because of leakage resulting from the lack of radial symmetry of the Vycor tubing, it was necessary to provide an auxiliary closure having a truly circular opening. The stainless steel head adopted for this purpose was fitted with a rubber O-ring, which was compressed against the outer wall of the tubing to accommodate the ellipticity and give an adequate seal.

The desired electrode assembly was placed in the reactor, as shown in Figure A-2, which was evacuated to about $10 \mu$ pressure. The pressure within the tube was then adjusted to atmospheric by helium which had been passed over a zirconium getter to remove traces of oxygen, nitrogen, and water vapor.

The electrode assembly was removed and the reaction tube charged with the desired metal halide through a glass tube attached to a charging bottle. After the electrodes were replaced and connected, the liquid-nitrogen trap before the vacuum pump was charged and water routed to the condenser on the reaction tube. The reaction-tube furnace, Figure A-1, was positioned and connected and the system again evacuated.

When the pressure in the system reached $10 \mu$ or less, gettered helium was added to reach the desired operating pressure. The furnace surrounding the reaction tube was heated to a temperature slightly above the dew point of the halide. This prevented premature condensation of the halide on the walls. The bottom furnace was powered by a Variac operating through a Micromax controller, set at the temperature where the vapor pressure of the halide slightly exceeded the adjusted helium pressure in the tube. The filament or rod temperature was adjusted by a Variac, and the temperature of the filament was measured by an optical pyrometer* focused through the slit shown in Figure A-1.

The current increase caused by metal or carbide deposition was measured by the ammeter shown in Figure A-1. The filament temperature at which the rise occurred and the system pressure were recorded.

-Final temperatures were adjusted for emissivity and absorption by the Vycor tube wall. 


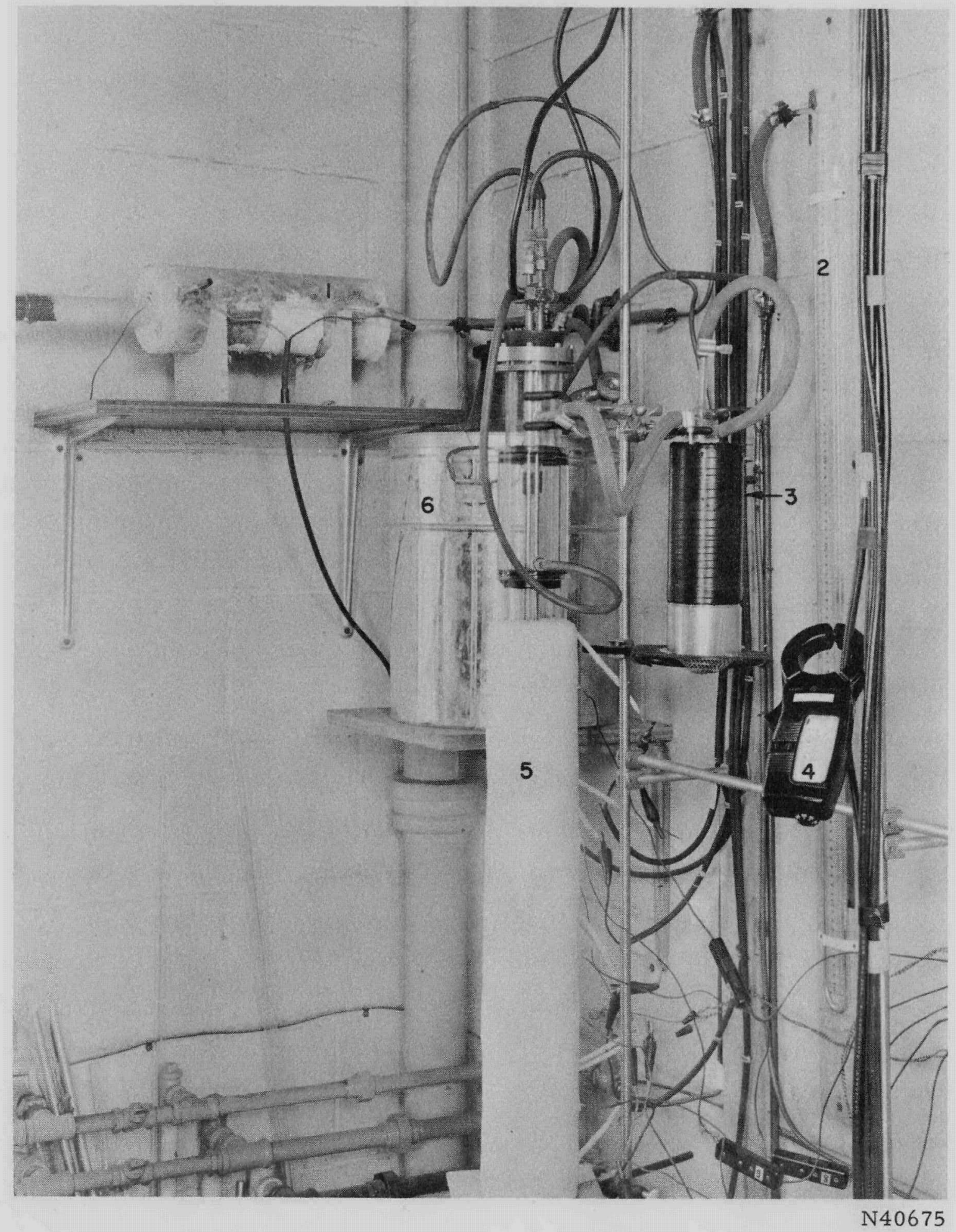

1. Gettering furnace

2. Manometer

3. Liquid nitrogen trap
4. Ammeter

5. Furnace with electrical and thermocouple leads attached

6. Surge Tank

FIGURE A-1. LIMITING-PRESSURE EQUIPMENT IN OPERATION

$2-36$

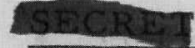

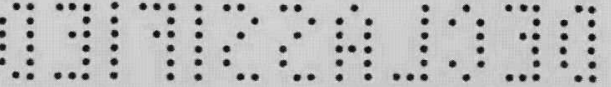




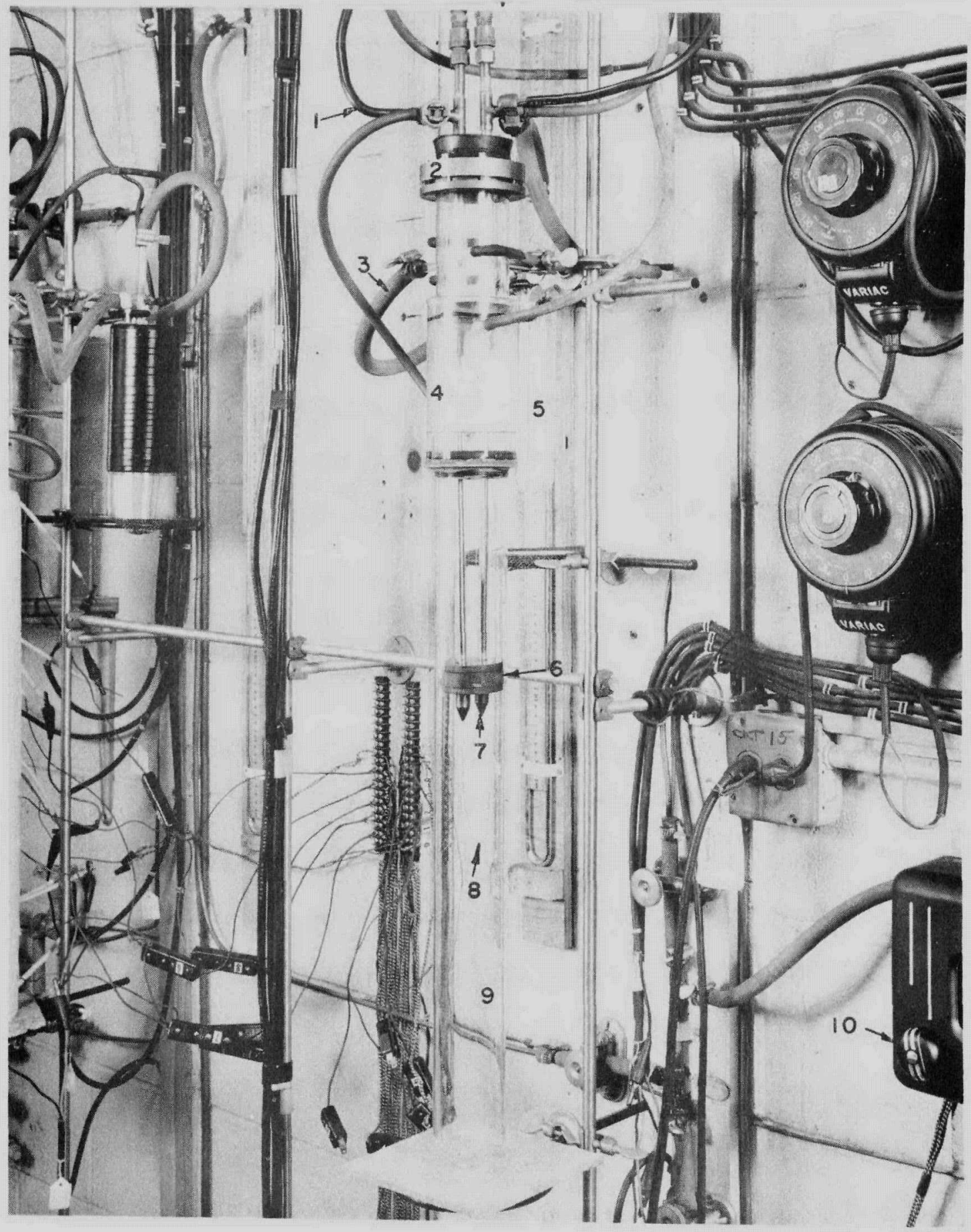

N40673

1. Electrical lead for heating element

2. O-ring vacuum head

3. Vacuum line

4. Water-cooled condenser

5. Trap
6. Split-ring vapor barrier

7. Molybdenum adaptor

8. Wire filament

9. Vycor reaction tube

10. McLeod gage

FIGURE A-2. LIMITING-PRESSURE EQUIPMENT SHOWING FILAMENT ASSEMBLY IN PLACE 


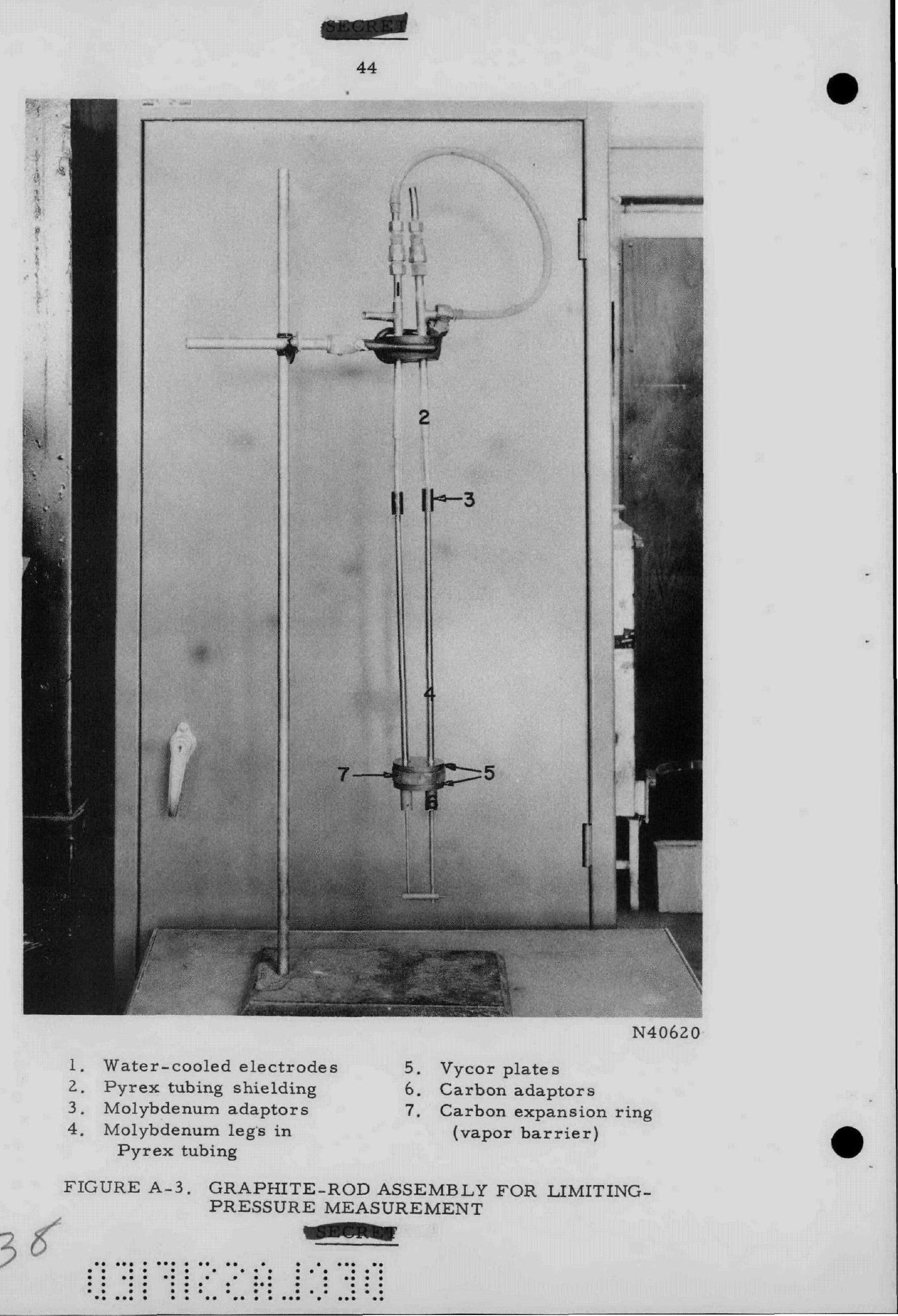


It may be asked whether the vapor barrier shown in Figures A-2 and A-3 was effective in maintaining a saturation partial pressure of halide vapor in the region of the filament without introducing a significant pressure drop. Its effectiveness is evidenced by the consistency of the data of Figures A-4 through A-10, taken over several runs for each system in which the vaporization rates varied over an appreciable range.

It will be noted that, for the deposition of zirconium from $\mathrm{ZrCl}_{4}$, it was necessary to work in the liquid range on a tungsten filament. The magnitude of the effect of alloying with the tungsten was not determined. Alloying would be expected to reduce the activity and make deposition in the alloy more favorable than deposition of pure metal, i.e., the experimentally determined limiting pressure would be on the high side. 


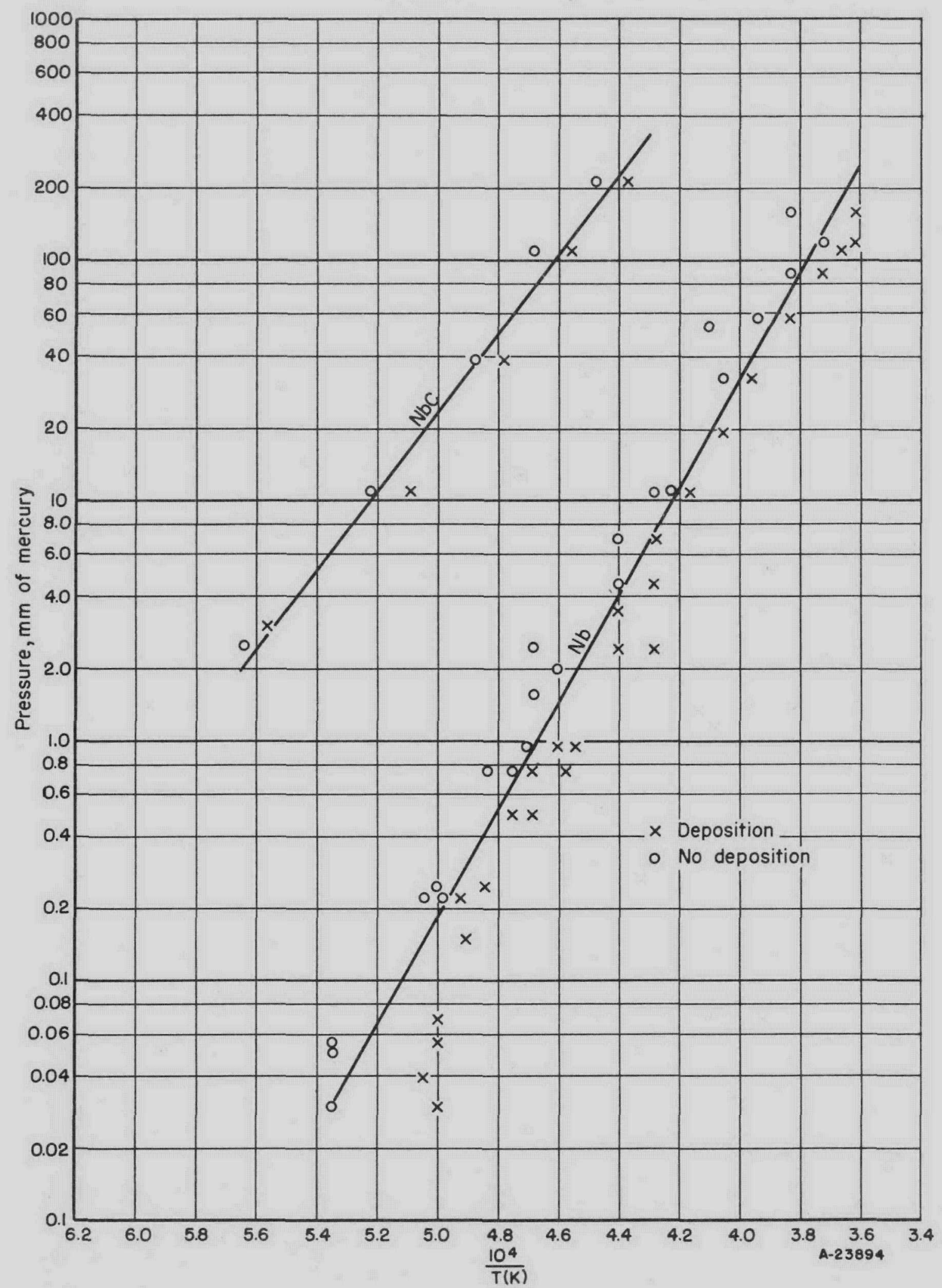

FIGURE A-4. CARBIDE FORMATION AND METAL DEPOSITION FROM NbCl 5 $2-40$ 


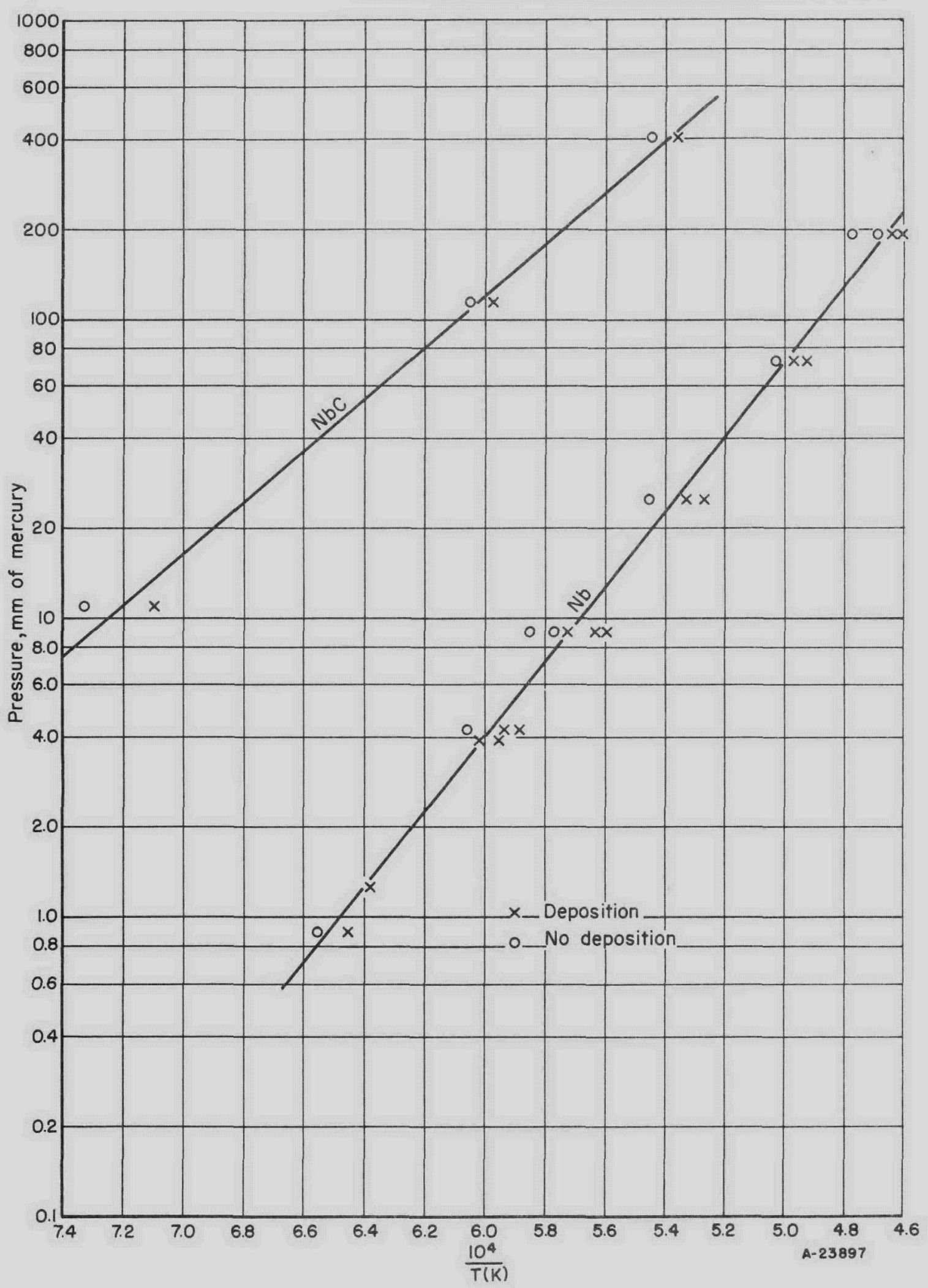

FIGURE A-5. CARBIDE FORMATION AND METAL DEPOSITION FROM NbBr 5 


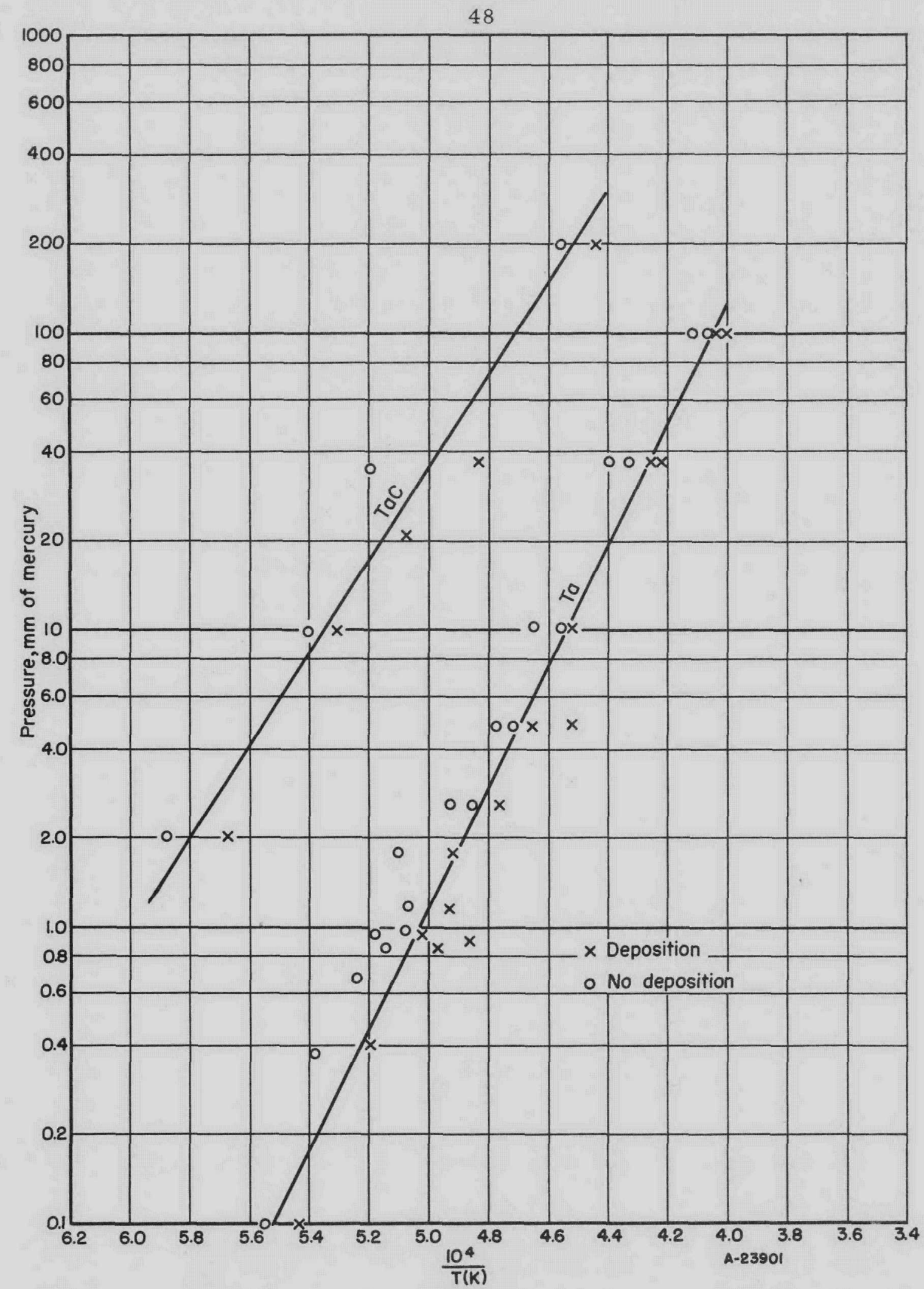

FIGURE A-6. CARBIDE FORMATION AND METAL DEPOSITION FROM TaCl 5 


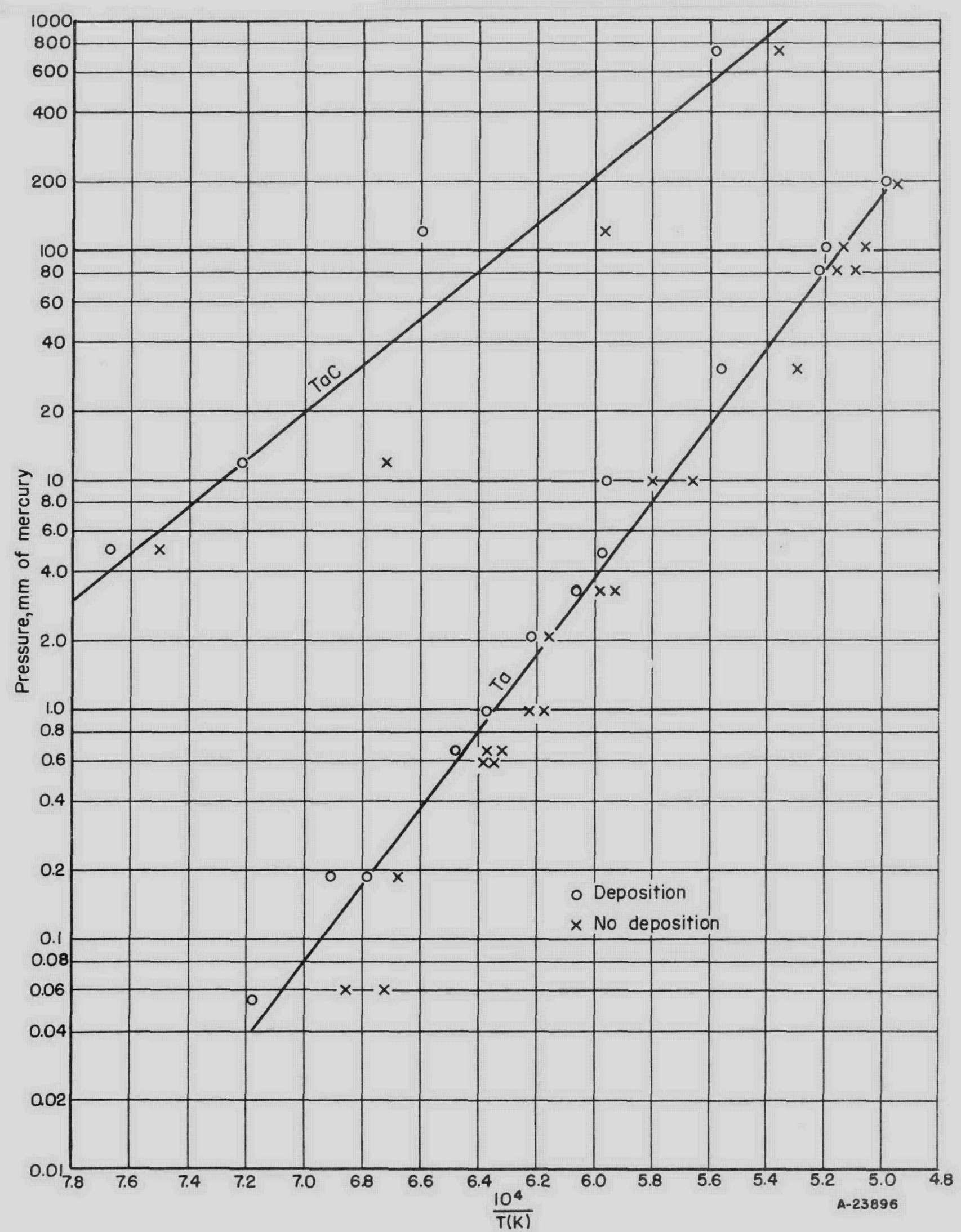

FIGURE A-7. CARBIDE FORMATION AND METAL DEPOSITION FROM TaBr 5 


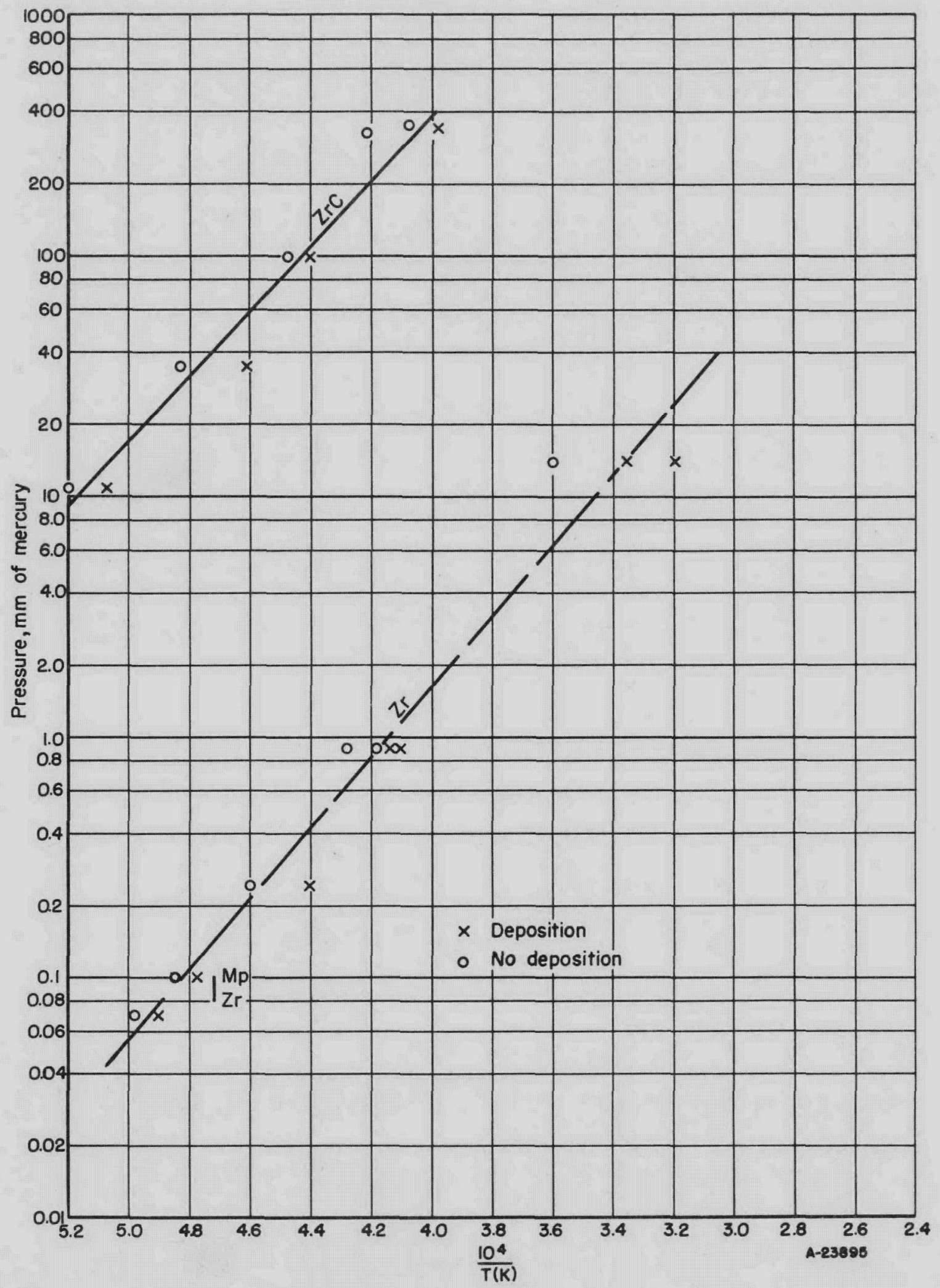

FIGURE A-8. CARBIDE FORMATION AND METAL DEPOSITION ON TUNGSTEN WIRE FROM $\mathrm{ZrCl}_{4}$ 


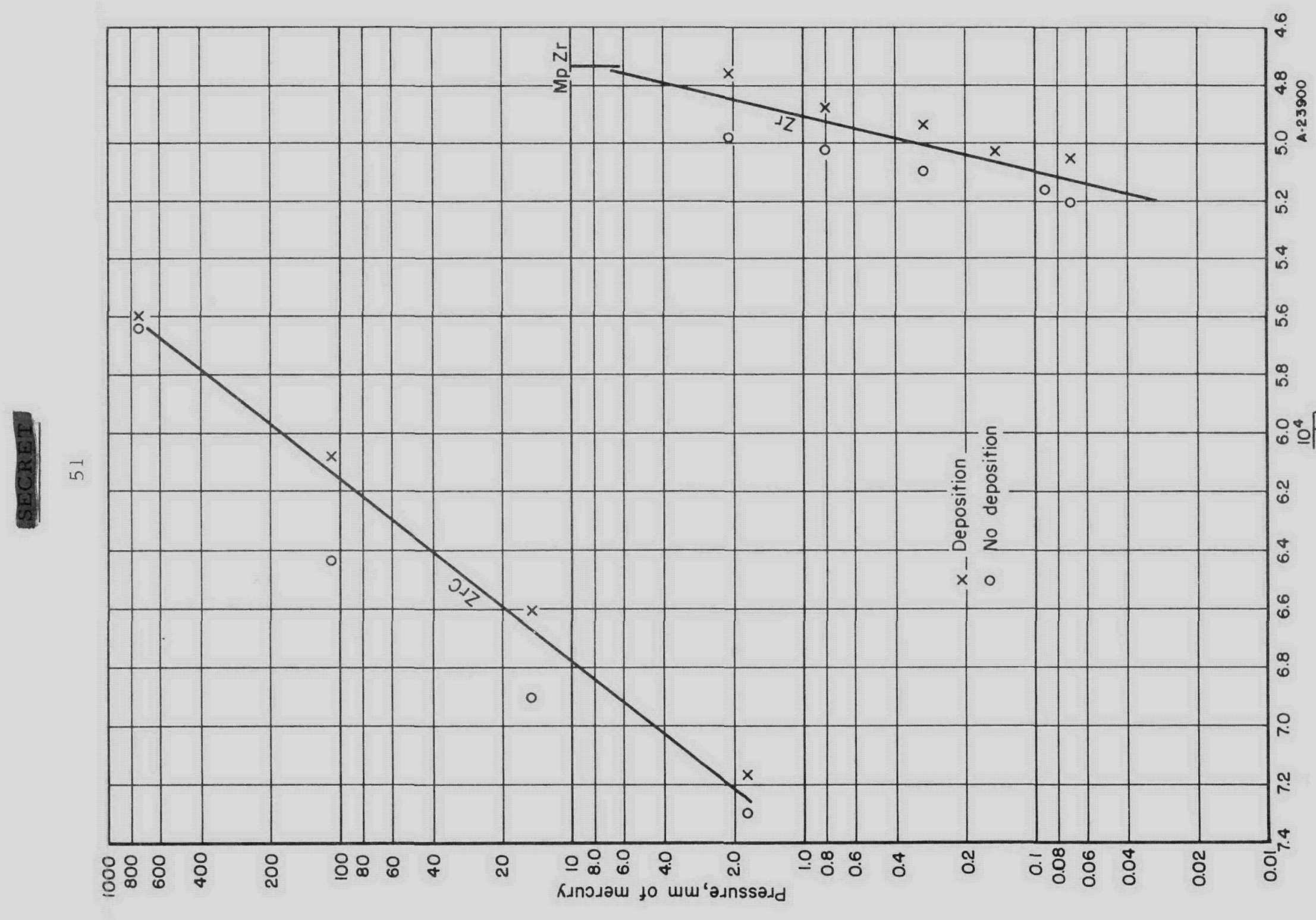

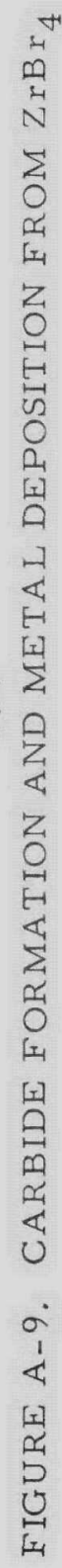

\section{L \\ $x$}

1

:....:

$\vdots . . . . \vdots$

…...

$\vdots . .$.

......

$\because \because$ :

$\because \because$ :

$\because \cdots$

.....

$\vdots . . .$.

:....: .

0 


\section{2}

$\frac{10^{4}}{T(K)}$

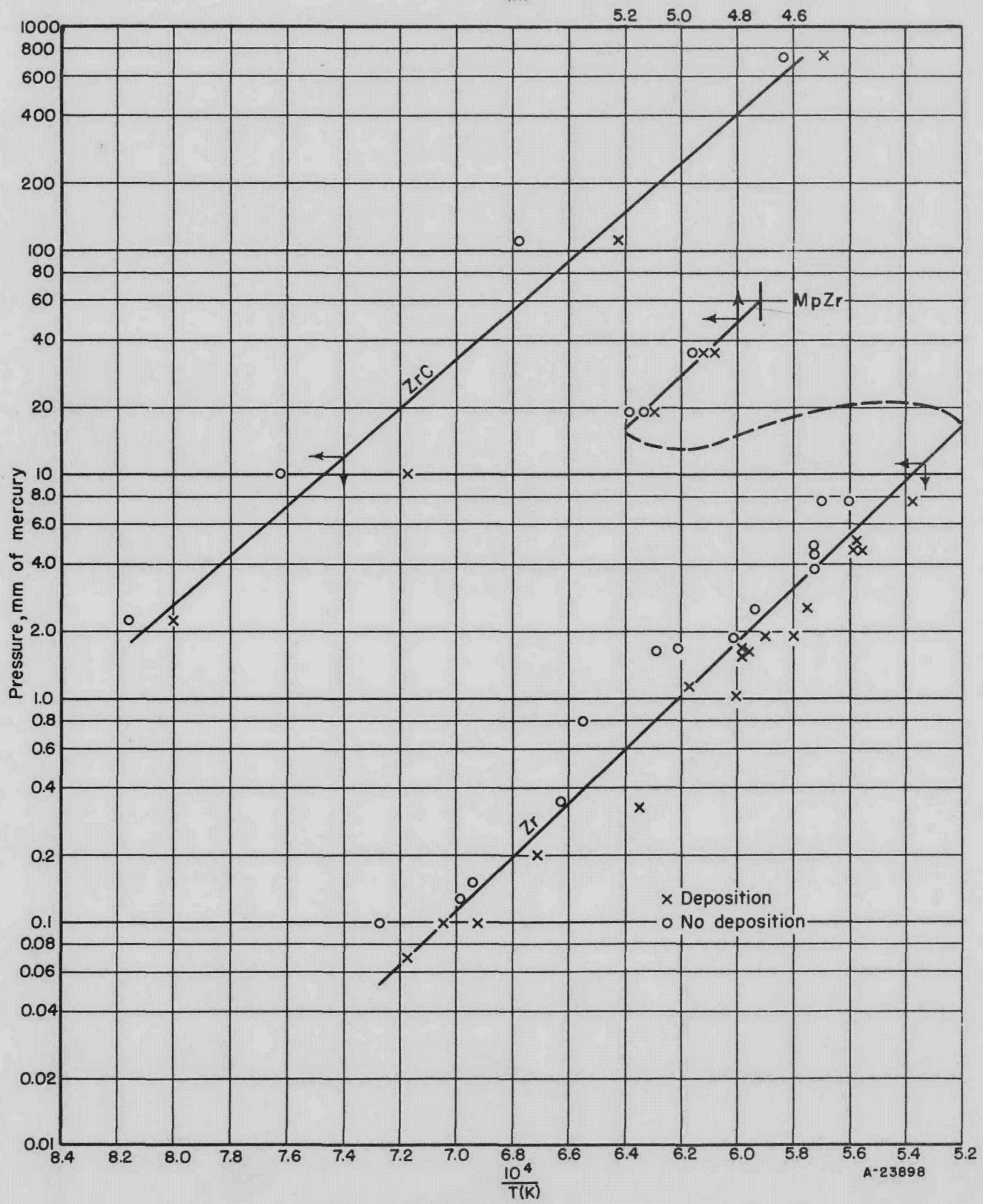

FIGURE A-10. CARBIDE FORMATION AND METAL DEPOSITION FROM ZrI 4

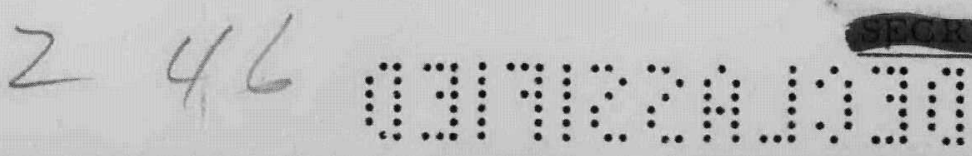




\title{
APPENDIX B
}

\section{COATING OF BLOWPIPE SPECIMENS}

\begin{abstract}
Material
With the exception of zirconium chloride, which was purchased from the Stauffer Chemical Company, the halides used in this work were synthesized from the elements, using high-purity materials. All were handled under an inert-gas blanket.
\end{abstract}

Apparatus

The coating equipment is described generally in the body of this report. Several details of interest are discussed here.

\section{Heating Circuits}

The specimen was heated by a thyratron-controlled Ignitron-fed transformer unit having a capacity of $2100 \mathrm{amp}$ at $29 \mathrm{v}$, made by the Federal Welding and Machine Company.

The vaporizer circuit was fed by a Transtat-controlled transformer system having a capacity of $500 \mathrm{amp}$ at $15 \mathrm{v}$.

It was found that at least $1060 \mathrm{amp}$ could be carried by $1 / 4$-in. copper tubing (0.032-in. wall) cooled by tap water at $42 \mathrm{gal}$ per $\mathrm{hr}$. The $36 \mathrm{~F}$ temperature rise of the water flowing through a 5 -ft length corresponded to a power loss of $3.7 \mathrm{kw}$. A tubing diameter of $3 / 8 \mathrm{in}$. was used in construction of the coating equipment, although the $1 / 4$-in. tubing would have been adequate.

\section{$\underline{\text { Vacuum System and Pressure Control }}$}

The coating equipment was evacuated by means of a Cenco Hypervac-25 pump through a liquid nitrogen-cooled trap and a glass-wool filter designed to catch entrained halide particles. An adjustable mercury manometer provided with electrical contacts and an electronic relay was used to control the pressure in the units by operating a solenoid valve which permitted intermittent pumping of an inert gas bleed.

\section{$\underline{\text { Typical Data }}$}

Tables B-1, B-2, and B-3 give typical data taken from Runs 13331-28-78LM, 13331-19-75LF, and 13331-73-93LF, respectively. Variations in coating thickness were obtained by varying the quantities of halide charged to the vaporizer.

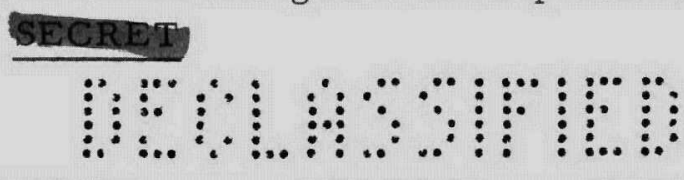


TABLE B-1. DATA FROM RUN 13331-28-78LM

$\begin{array}{ll}\text { Halide } & \mathrm{NbCl}_{5} \\ \text { Weight of Charge } & 255 \mathrm{~g} \\ \text { Pressure } & 50.0 \mathrm{~mm} \text { of mercury } \\ \text { Coating Temperature } & 2000 \mathrm{C}\end{array}$

\begin{tabular}{|c|c|c|c|c|c|}
\hline \multirow[b]{2}{*}{ Time } & \multirow{2}{*}{$\begin{array}{l}\text { Specimen } \\
\text { Current, } \\
\text { amp }\end{array}$} & \multirow{2}{*}{$\begin{array}{c}\text { Shield } \\
\text { Temperature, } \\
\text { F }\end{array}$} & \multicolumn{2}{|c|}{ Vaporizer } & \multirow[b]{2}{*}{ Remarks } \\
\hline & & & $\begin{array}{l}\text { Current, } \\
\text { amp }\end{array}$ & $\begin{array}{c}\text { Temperature, } \\
F\end{array}$ & \\
\hline 0930 & -- & -- & -- & -- & $\begin{array}{l}\text { Unit assembled and } \\
\text { evacuated }\end{array}$ \\
\hline 1010 & 65 & - & -- & -- & $\begin{array}{l}\text { Specimen fired and pres- } \\
\text { sure brought to } 50.0 \mathrm{~mm} \\
\text { of mercury with helium }\end{array}$ \\
\hline 1015 & 440 & -- & -- & -- & Power raised to specimen \\
\hline 1025 & 445 & -- & -- & -- & -- \\
\hline 1035 & 440 & -- & -- & -- & -- \\
\hline 1045 & 440 & -- & -- & 120 & -- \\
\hline 1050 & 440 & -- & -- & 125 & Vaporizer coolant drained \\
\hline 1055 & 440 & 1400 & 160 & 160 & Vaporizer fired \\
\hline 1100 & 445 & -- & 160 & 385 & -- \\
\hline 1105 & 450 & -- & 165 & 460 & --- \\
\hline 1110 & 450 & 1410 & 165 & 470 & -- \\
\hline 1120 & 455 & -- & 185 & 490 & Vaporizer power raised \\
\hline 1130 & 460 & 1440 & 200 & 520 & Vaporizer power raised \\
\hline 1140 & 465 & -- & 215 & 570 & Vaporizer power raised \\
\hline 1150 & 470 & 1440 & 235 & 630 & Vaporizer power raised \\
\hline 1155 & 475 & -- & 235 & 650 & -- \\
\hline 1200 & -- & -- & -- & -- & All power off \\
\hline 1300 & -- & -- & -- & -- & $\begin{array}{l}\text { Pressure brought with } \\
\text { helium to atmospheric } \\
\text { and unit opened }\end{array}$ \\
\hline
\end{tabular}

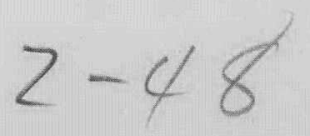




\author{
Halide \\ Weight of Charge \\ Pressure \\ Coating Temperature
}

$\mathrm{TaCl}_{5}$

$395 \mathrm{~g}$

$100 \mathrm{~mm}$ of mercury

$2000 \mathrm{C}$

\begin{tabular}{|c|c|c|c|c|c|}
\hline \multirow[b]{2}{*}{ Time } & \multirow{2}{*}{$\begin{array}{l}\text { Specimen } \\
\text { Current, } \\
\text { amp }\end{array}$} & \multirow{2}{*}{$\begin{array}{c}\text { Shield } \\
\text { Temperature, } \\
\text { F }\end{array}$} & \multicolumn{2}{|c|}{ Vaporizer } & \multirow[b]{2}{*}{ Remarks } \\
\hline & & & $\begin{array}{l}\text { Current, } \\
\text { amp }\end{array}$ & $\begin{array}{l}\text { Temperature, } \\
F\end{array}$ & \\
\hline 0900 & -- & -- & -- & -- & $\begin{array}{l}\text { Unit assembled and } \\
\text { evacuated }\end{array}$ \\
\hline 0945 & 65 & -- & -- & -- & Specimen fired \\
\hline 0950 & 460 & -- & -- & -- & $\begin{array}{l}\text { Pressure brought to } \\
100.0 \mathrm{~mm} \text { of mercury } \\
\text { with helium, power } \\
\text { raised }\end{array}$ \\
\hline 1000 & 445 & -- & -- & -- & -- \\
\hline 1010 & 440 & -- & -- & -- & -- \\
\hline 1020 & 440 & -- & -- & 130 & -- \\
\hline 1025 & 440 & 1400 & -- & 150 & Vaporizer coolant drained \\
\hline 1030 & 440 & -- & 160 & 200 & Vaporizer fired \\
\hline 1040 & 445 & -- & 100 & 490 & Vaporizer power raised \\
\hline 1050 & 455 & 1410 & 185 & 550 & +- \\
\hline 1100 & 460 & -- & 200 & 565 & Vaporizer power raised \\
\hline 1110 & 465 & 1420 & 205 & 600 & - \\
\hline 1120 & 465 & -- & 230 & 660 & Vaporizer power raised \\
\hline 1125 & 465 & 1440 & 250 & 710 & Vaporizer power raised \\
\hline 1130 & 465 & -- & 250 & 735 & -- \\
\hline 1135 & -- & -- & -- & -- & All power off \\
\hline 1230 & -- & -- & -- & -- & $\begin{array}{l}\text { Pressure brought to } \\
\text { atmospheric with } \\
\text { helium and unit opened }\end{array}$ \\
\hline
\end{tabular}


TABLE B-3. DATA FROM RUN 13331-73-93LF

$\begin{array}{ll}\text { Halide } & \mathrm{Z} \mathrm{rCl}_{4} \\ \text { Weight of Charge } & 170 \mathrm{~g} \\ \text { Pressure } & 5.0 \mathrm{~mm} \text { of mercury } \\ \text { Coating Temperature } & 2000 \mathrm{C}\end{array}$

\begin{tabular}{|c|c|c|c|c|c|}
\hline \multirow[b]{2}{*}{ Time } & \multirow{2}{*}{$\begin{array}{l}\text { Specimen } \\
\text { Current, } \\
\text { amp }\end{array}$} & \multirow{2}{*}{$\begin{array}{c}\text { Shield } \\
\text { Temperature, } \\
\text { F }\end{array}$} & \multicolumn{2}{|c|}{ Vaporizer } & \multirow[b]{2}{*}{ Remarks } \\
\hline & & & $\begin{array}{c}\text { Current, } \\
\text { amp }\end{array}$ & $\begin{array}{c}\text { Temperature, } \\
\mathrm{F}\end{array}$ & \\
\hline 1030 & -- & -- & -- & -- & $\begin{array}{l}\text { Unit assembled and } \\
\text { evacuated }\end{array}$ \\
\hline 1115 & -- & -- & -- & -- & $\begin{array}{l}\text { Pressure brought to } 5.0 \\
\text { mm of mercury with } \\
\text { helium }\end{array}$ \\
\hline 1120 & 65 & -- & -- & -- & Specimen fired \\
\hline 1125 & 430 & -- & -- & -- & Power raised \\
\hline 1135 & 425 & -- & -- & -- & -- \\
\hline 1145 & 420 & -- & -- & -- & -- \\
\hline 1155 & 420 & 1410 & -- & 150 & Vaporizer coolant drained \\
\hline 1200 & 420 & -- & 165 & 230 & Vaporizer fired \\
\hline 1210 & 420 & 1440 & 195 & 560 & -- \\
\hline 1220 & 420 & -- & 205 & 615 & Vaporizer power raised \\
\hline 1230 & 425 & 1470 & 210 & 645 & 16 $+2+$ \\
\hline 1240 & 425 & - & 220 & 675 & -- \\
\hline 1250 & 430 & 1470 & 220 & 700 & -- \\
\hline 1300 & 430 & -- & 240 & 715 & Vaporizer power raised \\
\hline 1310 & 430 & 1460 & 240 & 780 & -- \\
\hline 1320 & -- & -- & -- & -- & All power off \\
\hline 1415 & -- & -- & -- & -- & $\begin{array}{l}\text { Pressure brought to } \\
\text { atmospheric with } \\
\text { helium and unit opened }\end{array}$ \\
\hline
\end{tabular}




\section{7 and 58}

\section{Atmospheric-Pressure Coater}

Runs 11661-50-1LM through 12416-47-19LF were made in a coating unit consisting of separate vaporizing, coating, and condensing chambers which was later abandoned. Difficulty was experienced in obtaining a vacuumtight, electrically insulated seal which would operate at the halide vaporization temperature, and accommodate the thermal expansion of the specimen. Consequently, use of the unit was limited to ZrC coating from $\mathrm{ZrI}_{4}$ where atmospheric pressure could be used. Unfortunately, this pressure is so close to the limiting pressure for metal deposition that, on occasion, convection currents, sweeping inert gas into the coating region, lowered the partial pressure of $\mathrm{ZrI}_{4}$ to the point that liquid zirconium formed and ran down the specimen. Some success was obtained when care was taken to avoid mixing of the vapor stream with the inert-gas blanket. 
Consider a simple example in which the metal halide $\mathrm{MX}_{5}$ dissociates to form the metal and halogen atoms*:

$$
M X_{5}(g)=M(s)+5 X(g) .
$$

Consider further that one lower halide, $M X_{n}(g)$ is stable, and that the equilibrium

$$
M X_{n}(g)=M(s)+n X(g)
$$

must be considered. At total pressures corresponding to the limiting pressure for metal deposition (see Figures 2 or 3 ), the pentahalide being fed to the hot surface is dissociated to halogen and the lower halide, but metal is neither deposited nor consumed. It seems reasonable to assume that, at the temperatures involved in this work, the vapor consists principally of lower halides and the halogen and that pentahalide (in this case) is unimportant.

Thus, the limiting pressure is defined by Equation (C-2) and the stoichiometry condition:

$$
(5-n) P_{M X}=P_{X}
$$

whence,

$$
P_{\text {limit }}=P_{M X}+P_{X}=(6-n) P_{M X}
$$

From Equation (C-2),

or

$$
\begin{gathered}
K_{2}=\frac{P_{X}^{n}}{P_{M X_{n}}}=(5-n)^{n} P_{M X_{n}}^{n-1} \\
P_{M X_{n}}=\frac{\frac{1}{K_{2}^{n-1}}}{(5-n)^{\frac{n}{n-1}}},
\end{gathered}
$$

and

$$
P_{\text {limit }}=\frac{(6-n)}{(5-n)^{\frac{n}{n-1}}} K_{2}^{\frac{1}{n-1}} .
$$

- It can be shown that at the temperatures and pressures of interest in this work, the halogens in question are predominantly mona tomic.
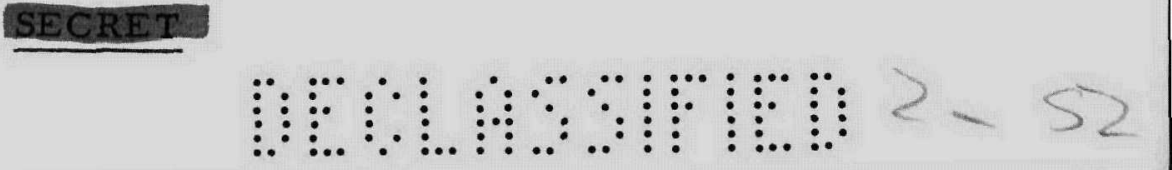
In logarithmic form:

$$
\log P_{M}=\log f(n)+\frac{1}{n-1} \log K_{2} *,
$$

where $P_{M}$ is the limiting pressure for metal deposition. Now, in the formation of carbide, the same stoichiometry condition holds at the limiting pressure and Equation $(\mathrm{C}-2)$ is replaced by Equation $\left(C_{-}-4\right)$ :

$$
M X_{n}(g)+C(s)=M C(s)+n X(g) \text {. }
$$

Since the gaseous constituents are the same, we have, corresponding to Equation (C-3),

$$
\log P_{M C}=\log f(n)+\frac{1}{n-1} \log K_{4} \text {, }
$$

and

$$
\log \mathrm{P}_{\mathrm{M}} / \mathrm{P}_{\mathrm{MC}}=\frac{1}{\mathrm{n}-1}\left[\log \mathrm{K}_{2}-\log \mathrm{K}_{4}\right]
$$

or

$$
\log P_{M} / P_{M C}=\frac{1}{n-1}\left(\frac{-\Delta F_{2}+\Delta F_{4}}{2.303 R T}\right) .
$$

It will be noted that Equations $(C-2)$ and $(C-4)$ differ by

$$
M(s)+C(s)=M C(s) \text {, }
$$

where $\Delta F_{8}=\Delta F_{4}-\Delta F_{2}$ is the free energy of formation of the carbide, $\Delta F_{M C}$, whence:

$$
\log P_{M C} / P_{M}=\frac{\Delta F_{M C}}{(n-1) 2.303 R T} \text {. }
$$

* It should be noted at this point that $\log K_{2}=(n-1) \log P_{M}$ and that $(n-1) \frac{d \log P_{M}}{d(1 / T)}=-\frac{\Delta H_{2}}{2.303 R}$.

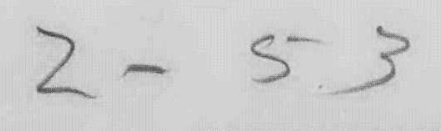

